\title{
EPOTHILONE D INHIBITS MICROGLIA-MEDIATED SPREAD OF ALPHA-SYNUCLEIN
}

\section{AGGREGATES}

\author{
Dario Valdinocci ${ }^{1}$, Gary Grant ${ }^{1}$, Tracey Dickson ${ }^{2}$, Dean L. Pountney ${ }^{1 *}$ \\ ${ }^{1}$ Menzies Health Institute Queensland, Griffith University, Gold Coast, Australia; ${ }^{2}$ Menzies Institute for \\ Medical Research, University of Tasmania, Hobart, Australia.
}

Running title: EpoD inhibits alpha-synuclein spread by microglia

Keywords: multiple system atrophy, alpha-synuclein, microglia, epothilione D, microtubule.

*Corresponding author:

Dean L. Pountney

Menzies Health Institute Queensland,

School of Medical Science,

Griffith University,

Gold Coast, Queensland 4222,

Australia

Tel: +61755527273

Fax: +61755528908

Email: d.pountney@griffith.edu.au 


\section{Abstract}

Multiple System Atrophy (MSA) is a progressive neurodegenerative disease characterized by chronic neuroinflammation and widespread $\alpha$-synuclein ( $\alpha$-syn) cytoplasmic inclusions. Neuroinflammation associated with microglial cells is typically located in brain regions with $\alpha$-syn deposits. The potential link between microglial cell migration and the transport of pathological $\alpha$-syn protein in MSA was investigated. Qualitative analysis via immunofluorescence of MSA cases $(n=4)$ revealed microglial cells bearing $\alpha$-syn inclusions distal from oligodendrocytes bearing $\alpha$-syn cytoplasmic inclusions, as well as close interactions between microglia and oligodendrocytes bearing $\alpha$-syn, suggestive of a potential transfer mechanism between microglia and $\alpha$-syn bearing cells in MSA and the possibility of microglia acting as a mobile vehicle to spread $\alpha$-syn between anatomically connected brain regions. Further In vitro experiments using microglial-like differentiated THP-1 cells were conducted to investigate if microglial cells could act as potential transporters of $\alpha$-syn. Monomeric or aggregated $\alpha$-syn was immobilized at the centre of glass coverslips and treated with either cell free medium, undifferentiated THP-1 cells or microglial-like phorbol-12-myristate-13-acetate differentiated THP-1 cells ( $48 \mathrm{~h} ; \mathrm{n}=3$ ). A significant difference in residual immobilized $\alpha$-syn density was observed between cell free controls and differentiated $(p=0.016)$ as well as undifferentiated and differentiated THP-1 cells $(p=0.032)$ when analysed by quantitative immunofluorescence.

Furthermore, a significantly greater proportion of differentiated cells were observed bearing $\alpha$-syn aggregates distal from the immobilized protein than their non-differentiated counterparts $(p=0.025)$. Similar results were observed with Highly Aggressive Proliferating Immobilised (HAPI) microglial cells, with cells exposed to aggregated $\alpha$-syn yielding lower residual immobilized $\alpha$-syn $(p=0.004)$ and a higher proportion of $\alpha$-syn positive distal cells ( $p=0.001)$ than cells exposed to monomeric $\alpha$-syn. Co-treatment of THP-1 groups with the tubulin depolymerisation inhibitor, Epothilone D (EpoD; $10 \mathrm{nM}$ ), was conducted to investigate if inhibition of microtubule activity had an effect on cell migration and residual immobilized $\alpha$-syn density. There was a significant increase in both residual immobilized $\alpha$-syn between EpoD treated and non-treated differentiated cells exposed to 
monomeric ( $p=0.037)$ and aggregated $(p=0.018) \alpha$-syn, but not with undifferentiated cells.

Differentiated THP-1 cells exposed to immobilized aggregated $\alpha$-syn showed a significant difference in the proportion of distal aggregate bearing cells between EpoD treated and untreated $(p=0.027)$. The results suggest microglia could play a role in $\alpha$-syn transport in MSA, a role which could potentially be inhibited therapeutically by EpoD.

\section{Abbreviations}

$\alpha-$ syn $=\alpha$-Synuclein

EpoD = Epothilone $D$

MSA = Multiple System Atrophy

PD = Parkinson's Disease

CNS $=$ Central Nervous System

DLB $=$ Dementia with Lewy Bodies

LB $=$ Lewy Bodies

$\mathrm{GCl}=$ Glial Cytoplasmic Inclusion

PMA = Phorbol-12-Myristate-13-Acetate

HAPI = Highly Aggressive Proliferating Immortalised 


\section{Introduction}

Multiple System Atrophy (MSA) is a sporadic progressive neurodegenerative disorder in which patients display signs of significant motor impairment, such as muscle rigidity and bradykinesia (Longo, Fanciulli and Wenning, 2015; Ubhi, Low and Masliah, 2011). MSA is commonly misdiagnosed as Parkinson's Disease (PD) due to the similarity in clinical phenotypes and age of onset over 50 (Wenning and Stefanova, 2009). The presence of additional symptoms, such as ataxia and autonomic dysfunction, however can distinguish MSA from PD (Wenning and Stefanova, 2009). Differences also exist with regard to both degeneration rate and sites of degeneration, with MSA patients typically having a more widespread and rapid onset of degeneration compared to PD patients. Survival rate comparisons show MSA patients living 8 years after symptom appearance compared to over 10 years for PD (Marttila and Rhine, 1991; Wenning and Stefanova, 2009; Williams et al., 2006). MSA is classified as an asynucleinopathy, in common with other diseases, including PD and Dementia with Lewy Bodies (DLB), brought about by the presence of misfolded and aggregated pathological forms of the protein $\alpha$-synuclein ( $\alpha$-syn) (Spillantini and Goedert, 2000).

$\alpha$-syn is a 140 amino acid soluble protein predominantly expressed within the central nervous system (CNS) the normal role of which is currently unknown (Surguchov, 2015; Barbour et al., 2008; Theillet et al., 2016; Weinreb et al., 1996). Multiple studies have proposed a variety of roles including regulation of synaptic vesicle recycling, regulating SNARE protein activity and dopamine production (Burre et al. 2010; Perez et al., 2002; Larsen et al., 2006; Yavich et al., 2004; Yavich, Jäkälä and Tanila, 2006). Contention exists as to the normal conformation of the protein, however work from Burre et al and Theillet et al. indicates that $\alpha$-syn exists as an unfolded monomer within the cytosol but adopts a tetramer conformation with $\alpha$-helical content when interacting with lipid membranes (Burré et al., 2013; Theillet et al., 2016; Bartels, Choi and Selkoe, 2011; Jakes, Spillantini and Goedert, 1994; Luth et al., 2015). $\alpha$-Syn in $\alpha$-synucleinopathies exists in an oligomeric $\beta$-sheet conformation, allowing for further aggregation into fibrils and the formation of inclusion bodies. $\alpha$ - 
Syn inclusion bodies are the hallmark of $\alpha$-synucleinopathies, with each $\alpha$-synucleinopathy characterized by inclusion body pathology affecting different brain regions and cell types. .

In MSA inclusion bodies termed Glial Cytoplasmic Inclusions (GCI) occur predominantly within oligodendrocytes and astrocytes, and are composed of $\alpha \mathrm{B}$-crystallin and tau in addition to neurofilament, ubiquitin and oligomeric $\alpha$-syn (Miki et al., 2010; Tu et al., 1998). Aggregation into fibrils is thought to occur accompanied by phosphorylation at Serine 129, and adoption of the oligomeric $\beta$-sheet conformation (Cookson, 2009). Additional factors implicated in aggregation include oxidative stress and raised metal ion concentration, such as $\mathrm{Ca}^{2+}$, within neurons (Esteves et al., 2011; Danzer et al., 2007). MSA has been classified as a prion disease (Prusiner et al., 2015) and it is proposed that pathological fibrillar $\alpha$-syn is taken up by healthy cells and catalyzes the conversion of endogenous $\alpha$-syn monomer from the normal (non-prion) form to the misfolded protofibrillar (prion) form, followed by further transfer to or infection of nearby regions and production of widespread GCls (Prusiner et al., 2015). This interaction affects conformation, changing the normal monomeric $\alpha$-syn into the oligomeric $\beta$-sheet form.

The presence of $\mathrm{GCls}$ within oligodendrocytes affects myelin production, creating a situation whereby trans-synaptic signalling by neurons is affected. $\alpha$-Syn is predominantly expressed within neuronal cells and levels of $\alpha$-syn expressed within oligodendrocytes in both healthy and diseased conditions were shown to be insignificant implying that uptake of $\alpha$-syn by glial cells occurs in MSA (Asi et al., 2014; Djelloul et al., 2015). Spread of pathology in MSA occurs via one of two pathways based on the subcategory of MSA, with both types displaying differing clinical phenotypes based on pattern of spread. In MSA-P, the presence of $\mathrm{GCls}$ and subsequent degeneration originates within the nigrostriatal region and spreads towards the frontal cortex, with patients displaying Parkinsonian-like symptoms(Paviour et al., 2007). In MSA-C, individuals display symptoms such as gait and limb ataxia due to the pathology originating from the cerebellum in the subcortical white matter and spreading to the motor cortex, substantia nigra and pons (Halliday et al., 2011; 
Brettschneider et al., 2016). Currently, exosome-mediated exchange of $\alpha$-syn between neurons and oligodendrocytes is implicated as one likely mechanism of the spread of brain pathology in MSA, with exosomes implicated also in the spread of $\alpha$-syn in other synucleinopathies (Frohlich et al., 2014, Reyes et a., 2013). Given the rapid progress of degeneration in MSA, other transportation mechanisms may also exist to mediate the cell-to-cell spread of $\alpha$-syn aggregates.

Another distinguishing feature of MSA compared to other $\alpha$-synucleinopathies is widespread gliosis in affected regions, including microglial cell activation. Microglia, the resident phagocytic immune cell of the CNS, become activated when interacting with or detecting pathological $\alpha$-syn and attempt to promote clearance via phagocytosis as well as recruiting additional cells via the release of proinflammatory factors (Interleukin- $\beta$ and Tumour Necrosis Factor- $\alpha$ ) (Neumann, Kotter and Franklin, 2008). Currently, microglial activation has been shown to be mediated via interaction with Toll-Like Receptor 4 or Scavenger Receptor CD36 with $\alpha$-syn, both of which can elicit the release of proinflammatory cytokines (Su et al., 2008; Stefanova et al., 2011; Kim et al., 2013; Roodveldt et al., 2013; Fellner et al., 2013; Tang and Le, 2015; Asai et al., 2015; Radford et al, 2015; Vieira et al, 2015). This activation is also accompanied by a morphological change in the microglial cell, from a ramified surveillant state to an amoebic phagocytic one (Jonas et al., 2012; Perry, Cunningham and Holmes, 2007). Both PD and DLB also display neuroinflammatory profiles, although less severe than in MSA, with an increase in the presence of pro-inflammatory cytokines likely due to increased microglial activation (Kaufman et al., 2013; Wenning and Stefanova, 2009 ; Koga et al., 2015; Nagatsu and Sawada, 2005; Tufekci et al., 2012; Higuchi et al., 2000). Furthermore, microglia can take-up exosomes released by oligodendrocytes via macropinocytosis and mediate degradation (Fitzner et al., 2011). Neuroinflammation and microglial activation/proliferation play crucial roles in MSA, and microglia may also have the potential to act as transporters $\alpha$-syn aggregates and propagate the spread of $\alpha$-syn pathology in MSA to distal brain regions during disease progression. 
Microglia possess a multitude of factors that could contribute to a potential role as a vehicle of $\alpha$-syn spread in MSA. Whilst capable of degrading monomeric $\alpha$-syn effectively, they are less able to degrade $\alpha$-syn fibrils potentially due to impairment of the lysosomal pathway (Chu et al., 2009; Alvarez-Erviti et al., 2010). Lack of effective degradation of pathological $\alpha$-syn taken up by microglia may mean that microglia can become transporters of the protein as they migrate away from the site of uptake. Mouse model experiments by Radford et al., revealed that microglial activation not only occurred at the site of $\alpha$-syn aggregate injection, but also in more distal brain regions (Radford et al., 2015). Microglia can be highly invasive cells, with deformation of the microglial cell body enabling active migration through the interstitium; a property that may aide the potential transport of $\alpha$-syn aggregate cargo. Evidence for microglia as potential vehicles for protein transport has been observed before in other neurodegenerative diseases. Asai et al., reported that microglia appear to be actively involved in the propagation of the tau proteinin Alzheimer's Disease, and that depletion of microglia in addition to the suppression of microglial exosome release significantly affected the deposition of tau protein in nearby cells (Asai et al., 2015). $\alpha$-syn aggregates are also known chemoattractants for microglia, with microglia attracted to the extracellular protein (Wang et al., 2015).

Taken together, MSA gliosis, the chemo-attractant property of $\alpha$-syn, microglial plasticity and inability to degrade $\alpha$-syn suggest microglia as a potential vehicle for $\alpha$-syn transport in disease. To investigate this hypothesis, brain tissues samples of MSA patients were fluorescently stained for evidence of microglia migrating with engulfed $\alpha$-syn as well as evidence of interactions between $\mathrm{GCl}$ affected oligodendrocytes and microglia. MSA tissue showed evidence of $\alpha$-syn-bearing microglia proximal and distal to $\alpha$-syn deposits. Additionally cell culture experiments were performed to investigate microglial cell behaviour when exposed to monomeric and aggregated $\alpha$-syn. Microglial cells showed immobilized $\alpha$-syn could be taken up efficiently and transported away from the site of immobilization. Moreover, treatment with the microtubule stabilizing drug, EpoD, could block microglia-mediated $\alpha$-syn transport without affecting uptake. This data suggests that microglia can 
act as an efficient vehicle mediating the spread of $\alpha$-syn pathology in MSA and that inhibiting microglial migration pharmacologically could have therapeutic potential to slow disease progression.

\section{Materials and Methods}

\section{Cell Culture}

Human THP-1 monocytes (ATCC ${ }^{\circledR}$ TIB-202 ${ }^{\text {TM }}$ ) were grown in RPMI 1640 medium with L-Glutamine, $10 \%$ foetal bovine serum, $\beta$-Mercaptoethanol $(0.05 \mathrm{mM})$ and penicillin/streptomycin at $37^{\circ} \mathrm{C}, 5 \%$ $\mathrm{CO}_{2}$. Cell growth was not allowed to exceed $1 \times 10^{6}$ cells $/ \mathrm{mL}$. Cells were incubated for 3 days with $5 \mathrm{ng} / \mathrm{mL}$ of phorbol 12-myristate 13 -acetate (PMA) to cause differentiation to a more microglia-like state, as described (Bowdish, 2011).

Rat Highly Aggressive Proliferating Immortalised (HAPI; Merck, SCC103) microglial cells were grown in Low Glucose DMEM medium (1g/L D-Glucose) with $5 \%$ foetal bovine serum and penicillin/streptomycin at $37^{\circ} \mathrm{C}, 5 \% \mathrm{CO}_{2}$. Medium was replaced every 3 days and were split 1:7-1:9 every 7-9 days. HAPI cells did not require differentiation to become more microglial-like.

1321N1 astrocytoma (ECACC 86030402 ) cells were grown in DMEM Medium (4.5g/L D-Glucose) with $10 \%$ foetal bovine serum, Glutamax and penicillin/streptomycin at $37^{\circ} \mathrm{C}, 5 \% \mathrm{CO}_{2}$. Medium was replaced every 3 days and growth was not allowed to succeed $1 \times 10^{6}$ cells $/ \mathrm{mL}$.

\section{Alpha-synuclein mobilization assay}

a-Syn was expressed in Escherichia coli and purified by anion exchange and gel permeation chromatography as described previously (Goodwin et al., 2013). Aggregated $\alpha$-syn was produced by incubation (overnight; $4{ }^{\circ} \mathrm{C}$ ) with $100 \mu \mathrm{M}$ of $\mathrm{Ca}^{2+}$ and $1 \mathrm{mM} \mathrm{H}_{2} \mathrm{O}_{2}$ as described (Goodwin et al., 2013). Either monomeric or aggregated $\alpha$-syn $(50 \mu \mathrm{M} ; 1 \mu \mathrm{L})$ was applied to the centre of sterile $12 \mathrm{~mm}$ coverslips and allowed to dry under sterile conditions. Once dried, this was repeated until a total of 
$3 \mu \mathrm{L}$ of dried monomeric or aggregated $\alpha$-syn was immobilized at the centre of the coverslip.

Coverslips were then placed in 24-well plates and $1.1 \mathrm{~mL}$ of medium containing 50,000 cells per well was added and incubated for $48 \mathrm{~h}$ at $37^{\circ} \mathrm{C}, 5 \% \mathrm{CO}_{2}$. Differentiated THP-1 and HAPI cells that were adherent were first trypsinized. Control wells consisted of monomeric or aggregated $\alpha$-syn incubated with culture medium only. To assess if exposure to cell culture media significantly dissolved the immobilized $\alpha$-syn protein, an additional set of control coverslips was also prepared, in which immobilized protein (monomeric and aggregated) was immediately fixed and stained without exposure to medium . After $48 \mathrm{~h}$, coverslips were then fixed (methanol:acetone, $4: 1 ; 10 \mathrm{mins}, 4{ }^{\circ} \mathrm{C}$ ), blocked (20\% normal horse serum, PBS) and incubated with primary and secondary antibodies for immunofluorescence. Primary antibodies were mouse anti- $\alpha$-syn (LB509) (Invitrogen) and rabbit anti-Iba1 (WAKO) both at 1:200 dilution. Secondary antibodies were Alexa Fluor ${ }^{\circledR} 488$ (AF488) Goat anti-mouse IgG (Life Technologies) and Alexa Fluor ${ }^{\circledR} 568$ (AF568) Donkey anti-rabbit IgG (Life Technologies) at 1:200 dilution. Coverslips were mounted on slides using Pro Long ${ }^{\circledR}$ Gold anti fade mountant with DAPI (Life Technologies). Additional parallel experiments were performed using Bovine Serum Albumin (BSA) in place of $\alpha$-syn. BSA was diluted to the same concentration as the $\alpha$ syn monomers and aggregates and was aggregated prior to being dried onto coverslips (Holm et al., 2007). Primary antibody for BSA was Invitrogen Bovine Serum Polyclonal Antibody (Product\#A11133) and secondary was Alexa Fluor ${ }^{\circledR} 568$ (AF568) Donkey anti-rabbit IgG (Life Technologies) both at 1:200 dilution.

\section{EpoD Treatment}

Cytotoxicity tests were performed using Promega ApoTox-Glo ${ }^{\mathrm{TM}}$ Triplex Assay in the presence of varying concentrations of EpoD at $0 \mathrm{nM}, 10 \mathrm{nM}, 25 \mathrm{nM}, 50 \mathrm{nM}$ and $100 \mathrm{nM}$. $\alpha$-Syn mobilization assays were conducted as above in the presence of 10nM EpoD. 
Human Tissue

Post-mortem human MSA-P brain tissue neuropathologically categorized as striatonigral degeneration subtype ( $n=4$; age at death $70 \pm 7$; post-mortem interval $8 \pm 3 h$; frontal cortex, motor cortex, basal ganglia and cerebellum) was from the South Australian Brain Bank (Griffith University Human Ethics: MSC/16/11/HREC). Formalin-fixed, paraffin-embedded sections (5 $\mu \mathrm{m}$; white and grey matter) were deparafined, rehydrated and subjected to heat induced antigen retrieval in $10 \mathrm{mM}$ EDTA pH 8, prior to blocking with $20 \%$ normal horse serum (NHS) / TBS. Sections were incubated overnight with primary antibodies (1:100; rabbit anti-Iba-1 (Novachem, USA); mouse anti- $\alpha$-syn (LB509; Abcam, UK) in $1 \%$ NHS-TBS prior to washing and application of secondary antibodies (1:200; Alexafluor AF488 and AF568). Sections were mounted using Pro Long ${ }^{\circledR}$ Gold anti fade reagent with DAPI (Life Technologies).

\section{Confocal Microscopy}

An Olympus Fluoview 1000 confocal laser-scanning confocal microscope was used to acquire all fluorescent images. Slides were imaged with the $10 x$ or $20 x$ lenses with numerical apertures of 0.4 and 0.45 respectively, or the $60 x$ oil immersion lens with a numerical aperture of 1.4 . The resolution for all images was $1024 \times 1024$ pixels. DAPI, AF488 and AF568 were imaged sequentially to prevent the possibility of fluorescent cross-excitation. Using Olympus FV-ASW 3.2 viewer, the images were false coloured and exported. Imaris software (version 6.4.2 Bitplane ${ }^{\circledR}$ ) was used for the 3D reconstructions of the confocal images. Negative controls slides stained with secondary antibodies only were used to establish specificity and set instrument parameters.

\section{Quantitative Analysis}

Residual immobilized $\alpha$-syn was determined from the mean immunofluorescence intensity. Confocal images were acquired at the centre and 2 edge regions (left, right) of the immobilized $\alpha$-syn on the coverslips. Each scan was at 10x magnification at a 10.0us/pixel scan rate at a 1024x1024 resolution. 
ImageJ was used to determine the mean gray value of each region (centre, right or left). Each region had 5 sub-regions ( $100 \times 100$ pixels) at specific co-ordinates as follows:- centre: top left $(0,0)$, top right $(11,0)$, middle $(6,6)$, bottom left $(0,11)$, bottom right $(11,11)$; right edge: top left $(0,0)$, intermediate $1(4,2)$ middle $(6,6)$, intermediate $2(4,9)$, bottom left $(0,11)$, left edge: top right $(11,0)$, intermediate $3(8,2)$ middle $(6,6)$, intermediate $4(8,9)$, bottom right $(11,11)$. Once the 5 mean gray values for each of the three regions were determined, the average was calculated. Overall mean gray values were produced for each experimental condition. Figure 3A (Top Row) illustrates the areas scanned in each image.

\section{Cell Counting}

Cells counting was performed at eight specific $20 x$ regions at the edge of each coverslip. Four of these edge locations were the top, right, left and bottom of the coverslip edge whilst the other four edge regions intermediate between these were termed Top Right, Top Left, Bottom Right and Bottom Left. Figure 4B illustrates counting regions of the coverslips. Cells were scored as $\alpha$-synpositive with distinct cytoplasmic immunofluorescence at least two times over background. Total cell counts were determined from the DAPI-stained nuclei.

\section{Data Analysis}

All data analysis used IBM SPSS Statistics 24 and 25. Independent t-tests were performed on the residual immobilized $\alpha$-syn and cell counting data between groups. ANOVA tests were also performed to assess statistical significance within groups and for the EpoD experiments with LSD Post-Hoc test. Significance was set at $\mathrm{p}=0.05$. 
Results

Microglial Cytoplasmic $\alpha$-syn in MSA

We utilized confocal immunofluorescence microscopy and image reconstruction of MSA brain tissue sections to investigate the relationship between $\mathrm{GCl}$-containing oligodendrocytes and activated microglia. Frequent Iba-1-positive microglia were observed in close proximity to $\mathrm{GCl}$-containing oligodendrocytes (Fig 1 \& 2). As presented in Fig $1 \mathrm{~A}-\mathrm{F}$ and 2B, many interactions are observed between activated microglia and $\mathrm{GCl}$-containing oligodendrocytes characterized by microglial processes apparently in contact with the oligodendrocytes. The microglial cells in these interactions often also had $\alpha$-syn present within the cytosol (Fig 1 D-F). Fig 2 illustrates a potential time-series of microglial migration and $\alpha$-syn uptake. The presence of $\alpha$-syn may be the result of phagocytic engulfment of extracellular $\alpha$-syn or may occur by direct transfer between microglia and oligodendrocytes. Fig $2 \mathrm{~A}$ shows an activated microglial cell in close proximity to a $\mathrm{GCl}$-affected oligodendrocyte that does not contain $\alpha$-syn within the cell. Fig $2 \mathrm{C}$ shows an activated microglial cell containing $\alpha$-syn in close proximity to $\mathrm{GCl}$-bearing oligodendrocyte, however not directly interacting. This juxtaposition may occur as microglial cells are chemoattracted towards $\alpha$-syn-affected regions then migrate away after acquiring protein or may be the result of migration towards the oligodendrocyte with $\alpha$-syn acquired previously. Evidence of oligodendrocytes expelling unwanted materials via exocytosis for microglial degradation exists, indicating that migration after acquisition is more likely (Fitzner et al., 2011).

Differentiated THP-1 cells take up immobilized $\alpha$-syn and migrate away

In order to investigate the potential for microglial cells to take up $\alpha$-syn and migrate away from the site of uptake, we designed a cell culture assay system. THP-1 human monocyte cells were 
differentiated to a microglial-like phenotype by treatment with PMA as described previously (Bowdish, 2011). Purified recombinant $\alpha$-syn monomer was immobilized by drying onto the centre of glass coverslips and incubated for $48 \mathrm{~h}$ with differentiated or undifferentiated THP-1 cells. In parallel experiments, $\alpha$-syn oligomeric aggregate was first prepared from the monomer by treatment with $100 \mu \mathrm{M} \mathrm{Ca}^{2+}$ and $1 \mathrm{mM} \mathrm{H}_{2} \mathrm{O}_{2}$ as described (Goodwin et al., 2013). A reduction in mean residual immobilized $\alpha$-syn would indicate that microglial-like cells are able to mobilize the protein. Residual immobilized $\alpha$-syn was measured by immunofluorescence confocal microscopy by determining the mean fluorescence intensity of a standard pattern of regions of interest across the immobilized protein as illustrated in Fig 3A (top panels). The boxes in Figure $3 \mathrm{~A}$ correspond to the regions analysed to obtain the mean $\alpha$-syn immunofluorescence intensity. Immunofluorescence effectively highlighted where $\alpha$-syn was immobilized at the centre of the coverslip. Incubation with differentiated cells yielded a marked reduction of residual immobilized $\alpha$-syn (lower panels) after 48 h.

Qualitative evidence of cells migrating with cytosolic $\alpha$-syn was also detected. Both THP-1 and differentiated THP-1 cells appeared to migrate toward the immobilized $\alpha$-syn monomer and aggregate forms. Figure 4B illustrates a typical cluster of undifferentiated THP-1 cells bearing aggregate $\alpha$-syn outside the immobilized $\alpha$-syn region (white arrows). This indicates that the cells have taken up protein and then migrated away from the $\alpha$-syn region. Similar $\alpha$-syn-positive cells were observed on coverslips with $\alpha$-syn monomer and when differentiated THP-1 cells were exposed to both $\alpha$-syn conformations. Figures 3B and 3C display differentiated cells carrying aggregated $\alpha$ syn in a region between the edge of the $\alpha$-syn spot and coverslip edge. Of note, one of the cells was observed leaking $\alpha$-syn content to the extracellular environment, presenting a potential mechanism by which $\alpha$-syn may escape from microglia. In Fig 3D, DIC overlay confirms the cytoplasmic localization of internalized $\alpha$-syn. 
To obtain a more quantitative view, mean residual immobilized $\alpha$-syn (monomer or aggregate) was determined for repeat experiments $(n=3)$ after incubation for $48 \mathrm{~h}$ with either undifferentiated or differentiated THP-1 cells. Fig 3E shows that there was no significant difference in residual immobilized $\alpha$-syn with and without cells for monomeric protein whereas Fig $3 \mathrm{~F}$ shows a significant $(p=0.049)$ reduction in mean residual immobilized $\alpha$-syn aggregate with differentiated THP-1 cells only.

Microglial-like differentiated THP-1 cells do not degrade $\alpha$-syn aggregate, but transport it away from the site of deposition

In order to investigate further the potential for microglial-like cells to transport $\alpha$-syn aggregate, we analysed the proportion of $\alpha$-syn aggregate-bearing THP-1 cells distal from the site of the immobilized protein in our $\alpha$-syn mobilization assay system. Fig $4 \mathrm{~A}$ shows that differentiated THP-1 cells bearing $\alpha$-syn (arrows) were detected at varying distances away from the region of the coverslip with immobilized protein, travelling as far away as the edge of the coverslip. We therefore counted the proportion of a-syn bearing cells at the edge of the coverslip in each experimental condition. A standard pattern of regions was imaged as indicted in Fig 4B. Fig 4C illustrates the typical distribution of cells imaged. Enlargements show representative differentiated and undifferentiated cells exposed to $\alpha$-syn monomer or aggregate, illustrating the larger cytoplasm of differentiated cells and the increased cytoplasmic $\alpha$-syn. Fig 4D shows that there was a significant $(p=0.05)$ increase in the proportion of $\alpha$-syn-positive cells at the coverslip edge only with differentiated THP-1 cells exposed to immobilized $\alpha$-syn aggregate.

THP-1 cells take up immobilized control BSA protein, but do not transport it

Both THP-1 and differentiated THP-1 cells were exposed to immobilized fibrillar BSA as a control protein with the intention of investigating if uptake, or transport of protein were specific 
mechanisms to $\alpha$-syn. BSA was immobilized under the same conditions as both monomeric and aggregated $\alpha$-syn $(50 \mu \mathrm{M}, 3 \mu \mathrm{L})$ and wells were loaded with identical cell numbers $(50,000$ per well). Similar to aggregated $\alpha$-syn, BSA did not significantly dissolve in the presence of cell growth medium $(p=0.281)$. As seen on Fig $5 A$ and $5 C$, fluorescence measurements of residual immobilized BSA exposed to both THP-1 and differentiated THP-1 cells produced results similar to those observed on cells exposed to monomeric $\alpha$-syn, with the only significant result existing between differentiated THP-1 cells exposed to BSA and differentiated THP-1 cells exposed to aggregated $\alpha$-syn $(p=0.01)$. Thus, fibrillar BSA was taken up from an immobilized protein deposit as efficiently as monomeric $\alpha$ syn. The proportion of BSA uptake positive cells distal from the immobilized protein at the coverslip edge were significantly lower than those observed for both THP-1 and differentiated THP-1 cells exposed to both monomeric and aggregated $\alpha$-syn. The low proportion of cells retaining BSA distal from the immobilized protein may be attributed to efficient degradation of BSA after uptake, a function that, as noted earlier, is impaired for $\alpha$-syn aggregates.

Microglial HAPI Cells display similar uptake and transport of $\alpha$-syn aggregates to Differentiated THP1 Cells

To support the results obtained with differentiated THP-1 cells the microglial-like HAPI cell line was exposed to the same conditions as the differentiated THP-1.. HAPI cells have been utilised in $\alpha$-syn migrational studies before and possess the lba-1 marker (Wang et al., 2015).As with the differentiated THP-1 cells, HAPI cells were either exposed to monomeric or aggregated $\alpha$-syn previously dried onto coverslips. The same $\alpha$-syn and Iba-1 fluorescent antibody markers used for THP-1 cells were utilized for HAPI. Similar to the differentiated THP-1 cells, HAPI cells with internalised $\alpha$-syn wereobserved both proximal and distal to the central immobilized protein spot. Significant differences between both HAPI groups were observed in both residual immobilized $\alpha$-syn and $\alpha$-syn-positive cell proportions at thecoverslip edge. There was significantly less residual immobilized $\alpha$-syn for HAPI cells exposed to aggregated $\alpha$-syn than for HAPI cells exposed to $\alpha$-syn 
monomer $(p=0.004)$. The proportions of cells transporting $\alpha$-syn to the coverslip edge was also significantly higher for HAPI exposed to aggregated $\alpha$-syn compared to monomer ( $p=0.001)$.

When comparing these results to the corresponding differentiated THP-1 groups, most results obtained were similar. The proportions of distal $\alpha$-syn-positive cells for HAPI and differentiated THP1 cells were not significantly different for both monomer $(p=0.100)$ and aggregated $\alpha$-syn groups $(p=0.172)$. Residual immobilized $\alpha$-syn was not significantly different between differentiated THP-1 and HAPI cells for aggregated $\alpha$-syn groups ( $p=0.960)$, however, a significant difference did exist between differentiated THP-1 and HAPI exposed to $\alpha$-syn monomer $(p=0.013)$. The mean levels of residual immobilized $\alpha$-syn recorded from coverslips exposed to HAPI cells had measurements closer to undifferentiated THP-1 cells than for differentiated THP-1 cells.

Astrocyte-like 1321N1 take up immobilized $\alpha$-syn to a lesser extent than microglial-like cells and do not transport $\alpha$-syn aggregates

Astrocytes are known to function alongside microglia in the neuroinflammatory response. To determine if astrocyte-like cells behaved similarly to microglia under our assay conditions, 1321N1 human astrocytoma cells were tested for $\alpha$-syn uptake and transport. Whilst $\alpha$-syn-positive 1321N1 cells were observed, this was only observed in the region of the immobilized protein. No 1321N1 cells on the coverslip edge were observed bearing $\alpha$-syn. It is likely that $1321 \mathrm{~N} 1$ cells that had settled on the immobilized $\alpha$-syn after being loaded into wells were able to take up $\alpha$-syn, but there is no evidence of transportation (data not shown).

Distal Cells Containing $\alpha$-syn are Decreased Following EpoD Treatment

The microtubule depolymerisation inhibitor EpoD inhibits microglial cell migration and $\alpha$-syn transport. As microglial migration requires extravasation of cells through the intercellular space, involving cell plasticity, we were interested to determine if inhibiting cytoskeletal dynamics could affect cell migration and $\alpha$-syn transport. We therefore conducted a series of experiments utilizing 
our $\alpha$-syn mobilization assay in the presence and absence of the microtubule depolymerization inhibitor, EpoD. The Promega ApoTox-Glo ${ }^{\mathrm{TM}}$ Triplex Assay was used to determine which concentration was most suitable for investigating if inhibition of microtubule activity affected immune cells ability to migrate away from the protein spot once protein is engulfed. As previously mentioned EpoD can be cytotoxic. Of the concentrations tested (10nM, 25nM, 50nM and 100nM), only $10 \mathrm{nM}$ revealed no significant difference compared to controls ( $p=0.55)$.

Fig 7 and 8 summarize the EpoD experiments. Fig 7A illustrates the typical images of residual $\alpha$-syn for EpoD treatments. Fig 7B \& C shows that EpoD treated cells were still able to take up $\alpha$-syn. Comparing the corresponding EpoD treated and non-treated groups via ANOVA (Fig 7D \& E), the differentiated THP-1 cells were found to have a significant difference $(p=0.037)$ whilst the undifferentiated cells did not $(p=0.923)$. The aggregated protein produced a very similar result with increased immunofluorescence in EpoD treated THP-1 and differentiated THP-1 cells. A similar pattern to the monomer protein emerged in the aggregate protein ANOVA tests, with no-significant difference existing between treated and non-treated THP-1 cells $(p=0.719)$ and a significant between the differentiated cells $(p=0.018)$. This indicates that EpoD reduced microglial-mediated transport of immobilized $\alpha$-syn.

To further analyse the effect of EpoD on microglial $\alpha$-syn transport, we conducted cell counting at the coverslip edge, distal from the immobilized $\alpha$-syn. The mean proportion of cells transporting protein was observed to be lower in all EpoD treated cases except for differentiated THP-1 cells exposed to monomeric $\alpha$-syn. Differentiated THP-1 exposed to $\alpha$-syn aggregate was the only case to produce a significant difference in the independent $t$-test comparison between the treated and nontreated counterparts $(p=0.043)$. Both THP-1 experiments, monomeric $\alpha$-syn $(p=0.072)$ and aggregated $\alpha$-syn ( $p=0.304$ ), did not produce significant differences, nor did the monomeric protein exposed to differentiated THP-1 $(p=0.204)$. Proportions for non-treated THP-1 groups were 0.168 and 0.125 for monomeric and aggregated $\alpha$-syn, respectively, whilst for differentiated THP-1 cells 
the mean proportion for monomeric $\alpha$-syn was 0.187 and 0.553 for aggregated $\alpha$-syn. Significance was observed between differentiated cells $(p=0.036)$ and comparison of aggregated protein between THP-1 and differentiated cells $(p=0.025)$. The only significant decrease was the comparison between differentiated cells exposed to aggregated $\alpha$-syn protein $(p=0.006)$ compared to the EpoD treated cells. Proportion comparisons for THP-1 cells exposed to monomer $(p=0.291)$ and aggregate $\alpha$-syn ( $p=0.118$ ) were insignificant as was the comparison between treated and non-treated differentiated cells exposed to monomeric $\alpha$-syn ( $p=0.683$ ). Observed in treated examples were higher numbers of cells not transporting $\alpha$-syn. This increase of non-transporting cells appears to be due to EpoD inhibiting the cells ability to migrate.

\section{Discussion}

We have investigated using both cell culture experiments and tissue analysis the potential of microglia as a transporter of $\alpha$-syn in MSA. The tissue analysis of human MSA brain tissue suggested that microglial cells may play a potential role as a transport vehicle for $\alpha$-syn. Microglial cells possess many factors that would make it advantageous as a transporter of $\alpha$-syn such as plasticity, which could potentially explain why pathological $\alpha$-syn deposits and degeneration are widespread in MSA patient brains. Revealed in the cell culture study was the potential of the microtubule inhibiting agent, EpoD, acting as a microglial transport inhibitor. With chronic inflammation playing a large role in MSA, a role that is necessitated by microglial activation, this may shed light on how microglial cells may play a detrimental role in disease progression.

The tissue analysis demonstrated that the results observed in the cell culture experiments were not only limited to in vitro. Examinations of different brain regions from different patients revealed that microglia seemingly interact with oligodendrocytes that contain $\mathrm{GCls}$. The $\mathrm{GCls}$ within the oligodendrocytes are distinguishable based on their size and their known triangular morphology (Tu et al., 1998). Many of these interactions, as seen in figures $1 A, 1 C, 1 D$ and $2 B$, reveal that some microglia possess $\alpha$-syn within the cytoplasm. The interactions between microglia and 
oligodendrocytes are based on the proximity and contact of their membranes. Microglial membranes and pseudopodia were observed by fluorescently marking Iba-1, a protein involved in the manipulation of F-actin on the cytoskeleton of microglial cells (Sasaki et al., 2001). In figure 1A, the microglial cell is making contact with the proximal infected oligodendrocyte via pseudopodia extending from the membrane. It is speculated that this interaction could perhaps mediate transfer of $\alpha$-syn between the cells, a concept that has already been shown to exist between neuronal and oligodendroglial cells (Reyes et al., 2013). As noted previously, oligodendrocytes are known to release unwanted materials via exocytosis for microglial phagocytosis (Fitzner et al., 2011). The events in Figure 2 may be reflective of this action, whereby GCl-infected oligodendrocytes are releasing $\alpha$-syn into the extracellular environment which microglia engulf and begin to migrate with. This may perhaps be why microglia are recruited to areas of the brain where pathological $\alpha$-syn and GCls are detected, leading to release of inflammatory cytokines which recruit more microglia causing the chronic inflammatory response observed in the disease.

Qualitatively and quantitatively, the cell culture experiments present evidence of the capability of microglia as a transporter. Both differentiated and non-differentiated THP-1 cells appear to migrate towards the immobilized $\alpha$-syn which supports previous works revealing that $\alpha$-syn is a chemoattractant for immune cells (Wang et al., 2015). Monocytes and microglial cells are known to engulf $\alpha$-syn, a clearance mechanism that could prevent $\alpha$-syn spread. There was a significant reduction of residual immobilized protein after exposure to differentiated THP-1 cells, consistent with $\alpha$-syn uptake. However there was a significant increase in the proportion of distal differentiated THP-1 cells carrying $\alpha$-syn when exposed to the aggregated protein. This suggests that microglial-like cells take up aggregated $\alpha$-syn efficiently but do not efficiently degrade it, then migrate away from the site of uptake. Non-differentiated monocytic THP-1 cells, were less effective at $\alpha$-syn uptake and transportation compared to microglial-like differentiated THP-1 cells likely due to monocytes predominantly acting as a supplemental factor in neuroinflammation, involved in additional immune cell recruitment and phagocytosis of smaller damaging agents (Ji et al., 2007; Jeong et al., 2013). 
Differentiated THP-1 cells exposed to $\alpha$-syn aggregate would be expected to engulf the protein and migrate away with greater retained, undgraded protein content than cells exposed to monomeric $\alpha$ syn as the aggregated form of the protein is the pathological form of $\alpha$-syn and thus poses greater risk to a biological system than the monomer. The 1321N1 astrocytoma cell experiments revealed that $\alpha$-syn uptake is not limited to monocytes and microglial-like cells, however transportation of $\alpha$ syn under the assay conditions is specific to microglial-like cells.

Experiments that examined BSA control protein exposure to differentiated and non-differentiated THP-1 cells revealed two main points. As previously discussed, reduced $\alpha$-syn monomer uptake and transportation are consistent with its lack of pathogenicity, a notion that appears to be supported by cells exposed to BSA protein. Fluorescent measurements from both BSA-exposed cell groups were closer to those recorded from $\alpha$-syn monomer loaded wells. When comparing the differentiated THP-1 groups, significant difference existed only between the BSA and aggregated $\alpha$-syn -loaded wells. The second point is that both differentiated and non-differentiated THP-1 cells displayed the ability to degrade internalized protein, as evidenced by the significantly lower proportions of distal BSA positive cells compared to the parallel monomeric and aggregated $\alpha$-syn experiments as shown in Fig 5B and D. Although the residual immobilized BSA measurements were very similar to those observed in the $\alpha$-syn monomer experiments, this is not reflected in the proportion of distal BSA positive cells. The BSA experiments had significantly lower proportions of distal BSA positive cells than for the distal $\alpha$-syn monomer positive cells in parallel studies, suggesting that both the THP-1 and differentiated THP-1 cells were more readily able todegrade internalized BSA than internalized monomeric $\alpha$-syn. Other works have shown that microglia actively degrade monomeric $\alpha$-syn whilst the current results indicate that both THP-1 and differentiated THP-1 cells can degrade $\alpha$-syn monomer (Webb et al., 2003). However, the significantly greater uptake of aggregated $\alpha$-syn by differentiated THP-1 cells could be due to the undifferentiated THP-1 cells reduced ability to take up the protein, reinforcing that the differentiated form of THP-1 acquires more characteristics displayed by microglia. 
HAPI are an immortalised rat microglial cell line and have been used in a number of neurodegenerative disease studies as a cell model of microglia, including use in the investigation of chemoattraction to $\alpha$-syn (Wang et al., 2015). The current work with HAPI cells supports previous findings in the literature in which the HAPI cells migrate toward aggregated $\alpha$-syn, a result which is also reflected by the differentiated THP-1 cells. Much like the differentiated THP-1 cells, and indeed microglia in tissue, HAPI appear to migrate away with aggregated $\alpha$-syn cargo after uptake of the immobilized protein.

Microtubules, a component of the cytoskeleton, are involved in the migration of motile cells (Akhmanova and Steinmetz, 2015). Microtubules are intimately involved in a number of cellular processes within microglial cells, such as plasticity and morphological changes (Abd-El-Basset, Prashanth and Ananth Lakshmi, 2004; Ilschner and Brandt, 1996). Additionally, cell migration is also regulated via microtubules, due to the position of the microtubule organizing centre (MTOC), the site where microtubules in the cell originate and extend from. This may be the most appropriate target in arresting microglial movement. Epothilone $D(E p o D)$ is a macrolide which inhibits microtubule activity by stabilising tubulin polymers. Microtubules exist in dynamic instability whereby binding of GTP to $\alpha \beta$-tubulin heterodimers leads to polymerisation and extension whilst hydrolysis of GTP to GDP leads to microtubule shrinkage (Mitchison and Kirschner, 1984; Akhmanova and Steinmetz, 2015). EpoD polymerizes $\alpha$ - and $\beta$-tubulin, leading to microtubule stability and inhibition of their dynamic activity (Goodin, Kane and Rubin, 2004). One of the advantages EpoD has over compounds such as taxols is the ability to cross the blood-brain barrier (Fellner et al., 2002; Hoffmann et al., 2008). Whilst it has not been used on microglial cells, EpoD has been shown to act on other neurological cells (Brunden et al., 2010;). Side-effects of the drug however are cytotoxicity, leading to symptoms such as nausea, diarrhoea and fatigue (Cheng, Bradley and Budman, 2008; Chou et al., 1998). 
The current data indicates that the role of microglia in MSA is more than solely as a component of chronic neuroinflammation. Treatment of cells with EpoD resulted in reduced removal of immobilized $\alpha$-syn by THP-1 cells and a reduced number of $\alpha$-syn bearing cells distal from the immobilized protein. Considering the function of the drug is to arrest microtubule dynamics, this may in part be due to inhibition of microtubule action. Microglia, much like other immune and mobile cells, requires assistance from the microtubule cytoskeleton to allow for the process of migration (Lively \& Schlichter, 2013). $\alpha$-Syn containing cells were still observed on coverslips of EpoD treated cells, revealing that EpoD does not completely halt the migrational ability of differentiated THP1 cells but more likely hinders it. Whilst further experimentation would need to be conducted in several other models, EpoD and other microtubule activity arresting agents may be of use for therapeutic treatment of patients with MSA in the future.

Microglia, much like macrophages, are derived from monocytes. Monocytes cross the blood-brain barrier and differentiate into microglial cells due to maturation factors present within the brain tissue (Yamasaki et al., 2014). Most work has focussed on the role of microglia in the MSA inflammatory state, with monocytes seen as an additional factor in the recruitment of more microglial cells. However, it can be speculated that infiltrating monocytes may play also a role in the transportation of $\alpha$-syn if albeit a smaller one in comparison to microglia.

Considering the modes of potential transfer of $\alpha$-syn between neurons and oligodendrocytes and microglia, one mechanism that may allow for this to occur is tunnelling nanotubes. Tunnelling nanotubes are small F-actin channels formed from membrane protrusions of cells, allowing for the exchange of cargo between cells (Gerdes, Rustom and Wang, 2013). Not only are these nanotubes known to be utilised by immunological cells, but they have been shown to be high jacked in prion diseases for the purpose of spread (Gousset et al., 2009). Recent work has also shown that $\alpha$-syn can be spread via tunnelling nanotubes between two cell types (Dieriks et al., 2017). It may be possible that infected oligodendrocytes deposit $\alpha$-syn into microglia via tunnelling nanotubes, vice versa or 
perhaps both. It may also be possible that $\alpha$-syn in MSA, may possess the ability to hijack systems such as mitochondrial transfer via tunnelling nanotubes to elicit greater spread.

Suppression of microglial activation or depletion of microglia in animal models of MSA may also prove to be useful in investigating whether widespread $\alpha$-syn deposition and degeneration is propagated by microglial cells. As previously mentioned, microglial depletion in an animal model of Alzheimer's disease showed microglial cells propagated tau protein (Asai et al., 2015). Furthermore, exploring whether microglia can be modulated to more effectively degrade $\alpha$-syn would be another important aspect to investigate.

Microglia, both in vitro and in vivo, display characteristics that suggest that they can act as a transporter of $\alpha$-syn in MSA. The current study provides a foundation for future investigations in animal models. Our finding that EpoD can inhibit microglial migration carrying $\alpha$-syn may also pave the way for therapeutic treatment for patients suffering MSA, by the inhibition of migration of $\alpha$-syn transporting cells.

\section{Acknowledgements}

The authors gratefully acknowledge the financial support of Griffith University, Menzies Health Institute Queensland and the Australian Research Council. 


\section{Figure Legends}

Figure 1. Confocal immunofluorescence of MSA Frontal Cortex. Yellow arrows correspond to GCls, white arrows correspond to engulfed $\alpha$-syn within microglia. [A] Microglial processes interacting with oligodendrocyte-containing a $\mathrm{GCl}$ (yellow arrow). Microglial cell is also carrying $\alpha$-syn within the cytosol (white arrow). [B] 3D reconstruction of [A] using Imaris Software. [C] Microglial cell above the GCl-affected oligodendrocyte. [D] GCl-affected oligodendrocyte below microglial cell in [C]. Pictured is the $\mathrm{GCl}$ in cytoplasm of oligodendrocyte (yellow arrow) as well as $\alpha$-syn in cytoplasm of microglial cell. Only the oligodendrocyte is seen as the microglial cell is above the oligodendrocyte. Similar interaction as in $[\mathrm{A}]$ between microglia and $\mathrm{GCl}$-containing oligodendrocyte. $[\mathrm{E}, \mathrm{F}] 3 \mathrm{D}$ reconstruction of $[C, D]$ in Imaris Software.

Figure 2. Potential time series that may occur in MSA based on three nearby regions of the same cerebellum. All images are Imaris reconstructions. [A] Activated microglial cell in close proximity to a $\mathrm{GCl}$-containing oligodendrocyte (yellow arrow). Note that there is no $\alpha$-syn within the cytosol of the microglial cell, a possible time point prior to interaction with oligodendrocytes. [B] Activated microglial cell making contact with $\mathrm{GCl}$-affected oligodendrocyte (yellow arrow) with $\alpha$-syn within its cytosol (white arrow). [C] Activated microglial cell with $\alpha$-syn in cytosol (white arrow) distant from GCl-containing oligodendrocyte (yellow arrow), possibly illustrates what occurs after microgliaoligodendrocyte interaction.

Figure 3. Differentiated THP-1 cells take up immobilized $\alpha$-syn aggregate and migrate away. [A] Example images of immobilized $\alpha$-syn incubated with or without THP-1 or differentiated THP-1 cells for $48 \mathrm{~h}$, illustrating left and right edge regions as well as the centre of the immobilized protein on the coverslip. The top row of images correspond to no cells control incubated with $\alpha$-syn monomer, whilst the row below are no cells control $\alpha$-syn aggregate. The middle 2 rows correspond to the undifferentiated THP-1 cells, $\alpha$-syn monomer and $\alpha$-syn aggregate, respectively. The bottom 2 rows correspond to differentiated THP-1 cells, $\alpha$-syn and $\alpha$-syn aggregate, respectively. The white boxes 
on the top row of images highlight the regions analysed by ImageJ to acquire Mean Gray Values. For details see materials and methods. Each image was taken at 10x magnification. [B] 60x magnification image of differentiated THP-1 cells bearing $\alpha$-syn aggregates. White arrows point to $\alpha$-syn-positive cells. [C] Enlargement of [B], displaying what appears to be the cell releasing $\alpha$-syn into the extracellular environment. [D] Combined DIC and confocal fluorescent image of differentiated cell exposed to $\alpha$-syn aggregate revealing that $\alpha$-syn aggregate (green) is contained within the cytosol of the differentiated cell. The cell was located between immobilized $\alpha$-syn region and coverslip edge. [E] Graph of residual immobilized $\alpha$-syn monomer. ANOVA showed no significant difference between any of the monomer groups. [F] Graph of residual immobilized $\alpha$-syn aggregate. ANOVA showed the only significant difference was between the no cells control and differentiated THP-1 cells $(*=p<0.05)$. Error bars are $+/-$ SEM.

Figure 4. Cell counting analysis reveals differentiated THP-1 do not degrade $\alpha$-syn aggregate, but transport away from the deposition site. [A] 20x Magnification image of the edge of an aggregated $\alpha$-syn region surrounded by undifferentiated THP-1 cells. White arrows point to cells transporting aggregated $\alpha$-syn. [B] Diagram of Coverslip. The green circle in the centre represents the immobilized $\alpha$-syn whilst the 8 red boxes correspond to the 8 regions of the coverslip where cell counts were conducted. These regions were designated as Top, Top Right, Top Left, Right, Left, Bottom, Bottom Right and Bottom Left. [C] Example images of regions where cell counts were conducted. An example is provided from each experimental condition, THP-1, monomeric $\alpha$-syn (Upper Left), THP-1, aggregate $\alpha$-syn (Upper Right), differentiated THP-1, monomeric $\alpha$-syn (bottom left) and differentiated THP-1 aggregated $\alpha$-syn (Bottom Right). All images were taken at 20x magnification. In the bottom left of each image is an enlarged view of an individual cell from that group using a combination of fluorescence and DIC. Images were at 60x magnification. [D] Graph of untreated wells displaying the mean percentage of cells observed on coverslip edge carrying $\alpha$-syn. Error bars are + /- SEM. $\quad *=p<0.05$. 
Figure 5. THP-1 cells take up immobilized control BSA protein, but do not transport it. A] Graph of residual immobilised protein comparing THP-1 groups exposed to monomeric and aggregate $\alpha$-syn against the THP-1 BSA control group. ANOVA showed no significant difference between any of the THP-1 groups. [B] Graph of proportions of protein positive THP-1 cells displaying the mean percentage of cells observed on coverslip edge carrying monomer $\alpha$-syn, aggregate $\alpha$-syn or BSA. Significantly lower BSA proportions observed in THP-1 compared to both $\alpha$-syn groups. [C] Graph of residual immobilised protein comparing Differentiated THP-1 groups exposed to monomeric and aggregate $\alpha$-syn against the Differentiated THP-1 BSA control group. ANOVA showed significant difference between differentiated cells exposed to aggregate $\alpha$-syn the BSA control. [D] Graph of proportions of protein positive Differentiated cells displaying the mean percentage of cells observed on coverslip edge carrying monomer $\alpha$-syn, aggregate $\alpha$-syn or BSA. Similar to THP-1, significantly lower BSA proportions observed in differentiated cells compared to both $\alpha$-syn groups. [E] Example immobilized BSA regions incubated with either non-differentiated or differentiated THP-1 cells. Left and right edge regions as well as the centre of the spot are shown. The upper row of images correspond to undifferentiated THP-1 whilst the lower row of three are differentiated THP-1. Each image was taken at 10x Magnification. [F] Example of regions counted at coverslip edge of BSA samples. Image on the left is the top left edge of a coverslip containing THP-1 cells exposed to BSA. The image on the right is of the bottom right edge of coverslip containing Differentiated THP-1 exposed to BSA .All images at 20x magnification.

Figure 6. HAPI Microglial-like Cells display similar $\alpha$-syn uptake and transport features to that of Differentiated THP-1 Cells. [A] Graph of residual immobilised monomeric $\alpha$-syn between THP-1, differentiated cells and HAPI. Significant difference existed between differentiated and HAPI cells. [B] Graph of proportion of $\alpha$-syn positive cells on coverslip edge between THP-1, differentiated and HAPI cells exposed to monomeric $\alpha$-syn. [C] Graph of residual immobilised aggregated $\alpha$-syn between THP-1, differentiated cells and HAPI. Significant difference existed between THP-1 and HAPI cells. [D] Graph of proportion of $\alpha$-syn positive cells on coverslip edge between THP-1, differentiated 
and HAPI cells exposed to aggregate $\alpha$-syn. Significance in cell proportions was observed between HAPI cells and non-differentiated THP-1 cells. Error Bars are $+/-$ SEM $(*=p<0.05)$. [E] Example immobilized $\alpha$-syn regions from each HAPI cell exposed condition. Left and right edge regions as well as the centre of the spot are shown. The upper row of images correspond to monomeric $\alpha$-syn whilst the lower row of three are aggregated $\alpha$-syn. Each image was taken at 10x Magnification. [F] Example of regions counted at coverslip edge of HAPI samples. Image on the left is the left edge of a coverslip containing HAPI cells exposed to monomeric $\alpha$-syn. The image on the right is of the top left edge of coverslip containing HAPI exposed to aggregate $\alpha$-syn .All images at 20x magnification.

Figure 7. EpoD inhibits microglial-mediated $\alpha$-syn mobilization. [A] Example immobilized $\alpha$-syn regions from each EpoD treated condition. Left and right edge regions as well as the centre of the spot are shown. The top 6 images correspond to THP-1; monomeric $\alpha$-syn for the upper row of images and the lower row of three aggregated $\alpha$-syn. The bottom 6 images correspond to differentiated THP-1 cells; monomer $\alpha$-syn for the upper row of images and aggregated $\alpha$-syn for the lower row. Each image was taken at 10x Magnification. $[B, C]$ Enlarged views of 60x magnification DIC and confocal overlay 10nM EpoD treated differentiated cells exposed to aggregated $\alpha$-syn. Both were taken in different wells and similar to their untreated counterpart, $\alpha$-syn (green) is observed in the cytoplasm of the cell. (B) Cell is binucleated due to differentiation process caused by PMA (Hornik, Neniskyte and Brown, 2013). (C) Processes of the differentiated cell are highlighted by DIC transmission light. These processes are similar to what is observed in microglial cells. Both cells were located in regions between the central immobilized $\alpha$-syn region and coverslip edge. [D] Graph comparing EpoD treated and untreated, monomeric $\alpha$-syn groups.[E] Graph comparing EpoD treated and untreated aggregated $\alpha$-syn groups. ${ }^{*}=p<0.05$. Error bars $+/-$ SEM.

Figure 8. Distal cells containing $\alpha$-syn are decreased following EpoD treatment. [A] Example images of regions were cell counts where conducted for the EpoD treated wells. Regions analysed in the treated group were the same as the untreated ones. Images from each well condition: THP-1 
Monomer $\alpha$-syn (Upper Left), THP-1 Aggregate $\alpha$-syn (Upper Right), Differentiated Cell Monomer $\alpha$ syn (Bottom Left) and Differentiated Cells Aggregate $\alpha$-syn (Bottom Right). All images were taken at 20x Magnification. In the bottom left of each image is a closer look at an individual cell from that group using a combination of fluorescent and DIC imagery. Images were zooms ups of scans taken at 60x magnification. [B] Graph of EpoD treated wells displaying the mean percentage of cells observed on coverslip edge carrying $\alpha$-syn. Error bars display the standard error. [C] Graph of Cell counts between untreated and 10nM EpoD treated wells of the same well condition. Percentages cell containing $\alpha$-syn at coverslip edge with Error bars displaying the standard error. ${ }^{*}=p<0.05$ 


\section{$\underline{\text { References }}$}

Abd-El-Basset, E., Prashanth, J. and Ananth Lakshmi, K. (2004). Up-Regulation of Cytoskeletal Proteins in Activated Microglia. Medical Principles and Practice, 13(6), pp.325-333.

Akhmanova, A. and Steinmetz, M. (2015). Control of microtubule organization and dynamics: two ends in the limelight. Nature Reviews Molecular Cell Biology, 16(12), pp.711-726.

Alvarez-Erviti, L., Seow, Y., Schapira, A., Gardiner, C., Sargent, I., Wood, M. and Cooper, J. (2011). Lysosomal dysfunction increases exosome-mediated alpha-synuclein release and transmission. Neurobiology of Disease, 42(3), pp.360-367.

Asai, H., Ikezu, S., Tsunoda, S., Medalla, M., Luebke, J., Haydar, T., Wolozin, B., Butovsky, O., Kügler, S. and Ikezu, T. (2015). Depletion of microglia and inhibition of exosome synthesis halt tau propagation. Nature Neuroscience, 18(11), pp.1584-1593.

Asi, Y., Simpson, J., Heath, P., Wharton, S., Lees, A., Revesz, T., Houlden, H. and Holton, J. (2014). Alpha-synuclein mRNA expression in oligodendrocytes in MSA. Glia, 62(6), pp.964-970.

Barbour, R., Kling, K., Anderson, J., Banducci, K., Cole, T., Diep, L., Fox, M., Goldstein, J., Soriano, F., Seubert, P. and Chilcote, T. (2008). Red Blood Cells Are the Major Source of Alpha-Synuclein in Blood. Neurodegenerative Diseases, 5(2), pp.55-59.

Bartels, T., Choi, J. and Selkoe, D. (2011). $\alpha$-Synuclein occurs physiologically as a helically folded tetramer that resists aggregation. Nature, 477(7362), pp.107-110.

Bowdish, D. (2011). Propagation \& culture of THP-1 cells. [online] Bowdish Lab. Available at: http://www.bowdish.ca/lab/wp-content/uploads/2011/07/THP-1-propagation-culture.pdf [Accessed 6 Jun. 2015]. 
Braak, H., Sandmann-Keil, D., Gai, W. and Braak, E. (1999). Extensive axonal Lewy neurites in Parkinson's disease: a novel pathological feature revealed by $\alpha$-synuclein immunocytochemistry. Neuroscience Letters, 265(1), pp.67-69.

Braak, H., Tredici, K., Rüb, U., de Vos, R., Jansen Steur, E. and Braak, E. (2003). Staging of brain pathology related to sporadic Parkinson's disease. Neurobiology of Aging, 24(2), pp.197-211.

Brettschneider, J., Irwin, D., Boluda, S., Byrne, M., Fang, L., Lee, E., Robinson, J., Suh, E., Van Deerlin, V., Toledo, J., Grossman, M., Hurtig, H., Dengler, R., Petri, S., Lee, V. and Trojanowski, J. (2017). Progression of alpha-synuclein pathology in multiple system atrophy of the cerebellar type. Neuropathology and Applied Neurobiology, 43(4), pp.315-329.

Brunden, K., Zhang, B., Carroll, J., Yao, Y., Potuzak, J., Hogan, A., Iba, M., James, M., Xie, S., Ballatore, C., Smith, A., Lee, V. and Trojanowski, J. (2010). Epothilone D Improves Microtubule Density, Axonal Integrity, and Cognition in a Transgenic Mouse Model of Tauopathy. Journal of Neuroscience, 30(41), pp.13861-13866.

Burre, J., Sharma, M., Tsetsenis, T., Buchman, V., Etherton, M. and Sudhof, T. (2010). $\alpha$-Synuclein Promotes SNARE-Complex Assembly in Vivo and in Vitro. Science, 329(5999), pp.1663-1667.

Burré, J., Vivona, S., Diao, J., Sharma, M., Brunger, A. and Südhof, T. (2013). Properties of native brain $\alpha$-synuclein. Nature, 498(7453), pp.E4-E6.

Cheng, K., Bradley, T. and Budman, D. (2008). Novel microtubule-targeting agents - the epothilones. Biologics, 2(4), pp.789-811.

Chou, T., Zhang, X., Balog, A., Su, D., Meng, D., Savin, K., Bertino, J. and Danishefsky, S. (1998). Desoxyepothilone B: An efficacious microtubule-targeted antitumor agent with a promising in vivo profile relative to epothilone B. Proceedings of the National Academy of Sciences, 95(16), pp.96429647. 
Chu, Y., Dodiya, H., Aebischer, P., Olanow, C. and Kordower, J. (2009). Alterations in lysosomal and proteasomal markers in Parkinson's disease: Relationship to alpha-synuclein inclusions.

Neurobiology of Disease, 35(3), pp.385-398.

Cookson, M. (2009). $\alpha$-Synuclein and neuronal cell death. Molecular Neurodegeneration, 4(1), p.9.

Daigneault, M., Preston, J., Marriott, H., Whyte, M. and Dockrell, D. (2010). The Identification of Markers of Macrophage Differentiation in PMA-Stimulated THP-1 Cells and Monocyte-Derived Macrophages. PLOS ONE, 5(1), p.e8668.

Danzer, K., Haasen, D., Karow, A., Moussaud, S., Habeck, M., Giese, A., Kretzschmar, H., Hengerer, B. and Kostka, M. (2007). Different Species of $\alpha$-Synuclein Oligomers Induce Calcium Influx and Seeding. Journal of Neuroscience, 27(34), pp.9220-9232.

Danzer, K., Kranich, L., Ruf, W., Cagsal-Getkin, O., Winslow, A., Zhu, L., Vanderburg, C. and McLean, P. (2012). Exosomal cell-to-cell transmission of alpha synuclein oligomers. Molecular Neurodegeneration, 7(1), p.42.

Dieriks, B., Park, T., Fourie, C., Faull, R., Dragunow, M. and Curtis, M. (2017). $\alpha$-synuclein transfer through tunneling nanotubes occurs in SH-SY5Y cells and primary brain pericytes from Parkinson's disease patients. Scientific Reports, 7, p.42984.

Djelloul, M., Holmqvist, S., Boza-Serrano, A., Azevedo, C., Yeung, M., Goldwurm, S., Frisén, J., Deierborg, T. and Roybon, L. (2015). Alpha-Synuclein Expression in the Oligodendrocyte Lineage: an In Vitro and In Vivo Study Using Rodent and Human Models. Stem Cell Reports, 5(2), pp.174-184.

Engelender, S. (2008). Ubiquitination of $\alpha$-synuclein and autophagy in Parkinson's disease. Autophagy, 4(3), pp.372-374.

Esteves, A., Arduíno, D., Silva, D., Oliveira, C. and Cardoso, S. (2011). Mitochondrial Dysfunction: The Road to Alpha-Synuclein Oligomerization in PD. Parkinson's Disease, 2011, pp.1-20. 
Fellner, S., Bauer, B., Miller, D., Schaffrik, M., Fankhänel, M., Spruß, T., Bernhardt, G., Graeff, C., Färber, L., Gschaidmeier, H., Buschauer, A. and Fricker, G. (2002). Transport of paclitaxel (Taxol) across the blood-brain barrier in vitro and in vivo. Journal of Clinical Investigation, 110(9), pp.13091318.

Fellner, L., Irschick, R., Schanda, K., Reindl, M., Klimaschewski, L., Poewe, W., Wenning, G. and Stefanova, N. (2013). Toll-like receptor 4 is required for $\alpha$-synuclein dependent activation of microglia and astroglia. Glia, 61(3), pp.349-360.

Fitzner, D., Schnaars, M., van Rossum, D., Krishnamoorthy, G., Dibaj, P., Bakhti, M., Regen, T., Hanisch, U. and Simons, M. (2011). Selective transfer of exosomes from oligodendrocytes to microglia by macropinocytosis. Journal of Cell Science, 124(3), pp.447-458.

Frohlich, D., Kuo, W., Fruhbeis, C., Sun, J., Zehendner, C., Luhmann, H., Pinto, S., Toedling, J., Trotter, J. and Kramer-Albers, E. (2014). Multifaceted effects of oligodendroglial exosomes on neurons: impact on neuronal firing rate, signal transduction and gene regulation. Philosophical Transactions of the Royal Society B: Biological Sciences, 369(1652), pp.20130510-20130510.

Galloway, P., Mulvihill, P. and Perry, G. (1992). Filaments of Lewy bodies contain insoluble cytoskeletal elements. American Journal of Pathology, 140(4), pp.809-822.

Gerdes, H., Rustom, A. and Wang, X. (2013). Tunneling nanotubes, an emerging intercellular communication route in development. Mechanisms of Development, 130(6-8), pp.381-387.

Goodin, S., Kane, M. and Rubin, E. (2004). Epothilones: Mechanism of Action and Biologic Activity. Journal of Clinical Oncology, 22(10), pp.2015-2025.

Goodwin, J., Nath, S., Engelborghs, Y. and Pountney, D. (2013). Raised calcium and oxidative stress cooperatively promote alpha-synuclein aggregate formation. Neurochemistry International, 62(5), pp.703-711. 
Gousset, K., Schiff, E., Langevin, C., Marijanovic, Z., Caputo, A., Browman, D., Chenouard, N., de Chaumont, F., Martino, A., Enninga, J., Olivo-Marin, J., Männel, D. and Zurzolo, C. (2009). Prions hijack tunnelling nanotubes for intercellular spread. Nature Cell Biology, 11(3), pp.328-336.

Halliday, G., Holton, J., Revesz, T. and Dickson, D. (2011). Neuropathology underlying clinical variability in patients with synucleinopathies. Acta Neuropathologica, 122(2), pp.187-204.

Higuchi, M., Tashiro, M., Arai, H., Okamura, N., Hara, S., Higuchi, S., Itoh, M., Shin, R., Trojanowski, J. and Sasaki, H. (2000). Glucose Hypometabolism and Neuropathological Correlates in Brains of Dementia with Lewy Bodies. Experimental Neurology, 162(2), pp.247-256.

Hoffmann, J., Fichtner, I., Lemm, M., Lienau, P., Hess-Stumpp, H., Rotgeri, A., Hofmann, B. and Klar, U. (2008). Sagopilone crosses the blood-brain barrier in vivo to inhibit brain tumor growth and metastases. Neuro-Oncology, 11(2), pp.158-166.

Holm, N., Jespersen, S., Thomassen, L., Wolff, T., Sehgal, P., Thomsen, L., Christiansen, G., Andersen, C., Knudsen, A. and Otzen, D. (2007). Aggregation and fibrillation of bovine serum albumin. Biochimica et Biophysica Acta (BBA) - Proteins and Proteomics, 1774(9), pp.1128-1138.

Hornik, T., Neniskyte, U. and Brown, G. (2013). Inflammation induces multinucleation of Microglia via PKC inhibition of cytokinesis, generating highly phagocytic multinucleated giant cells. Journal of Neurochemistry, 128(5), pp.650-661.

Ilschner, S. and Brandt, R. (1996). The transition microglia to a ramified phenotype is associated with the formation of stable acetylated and detyrosinated microtubules. Glia, 18(2), pp.129-140.

Jakes, R., Spillantini, M. and Goedert, M. (1994). Identification of two distinct synucleins from human brain. FEBS Letters, 345(1), pp.27-32.

Jellinger, K. (2014). Neuropathology of multiple system atrophy: New thoughts about pathogenesis. Movement Disorders, 29(14), pp.1720-1741. 
Jeong, H., Ji, K., Min, K. and Joe, E. (2013). Brain Inflammation and Microglia: Facts and Misconceptions. Experimental Neurobiology, 22(2), p.59.

Ji, K., Yang, M., Jeong, H., Min, K., Kang, S., Jou, I. and Joe, E. (2007). Resident microglia die and infiltrated neutrophils and monocytes become major inflammatory cells in lipopolysaccharideinjected brain. Glia, 55(15), pp.1577-1588.

Jonas, R., Yuan, T., Liang, Y., Jonas, J., Tay, D. and Ellis-Behnke, R. (2012). The Spider Effect: Morphological and Orienting Classification of Microglia in Response to Stimuli in Vivo. PLOS ONE, 7(2), p.e30763.

Kaufman, E., Hall, S., Surova, Y., Widner, H., Hansson, O. and Lindqvist, D. (2013). Proinflammatory Cytokines Are Elevated in Serum of Patients with Multiple System Atrophy. PLOS ONE, 8(4), p.e62354.

Kim, C., Ho, D., Suk, J., You, S., Michael, S., Kang, J., Joong Lee, S., Masliah, E., Hwang, D., Lee, H. and Lee, S. (2013). Neuron-released oligomeric $\alpha$-synuclein is an endogenous agonist of TLR2 for paracrine activation of microglia. Nature Communications, 4, p.1562.

Koga, S., Aoki, N., Uitti, R., van Gerpen, J., Cheshire, W., Josephs, K., Wszolek, Z., Langston, J. and Dickson, D. (2015). When DLB, PD, and PSP masquerade as MSA. Neurology, 85(5), pp.404-412.

Larsen, K., Schmitz, Y., Troyer, M., Mosharov, E., Dietrich, P., Quazi, A., Savalle, M., Nemani, V., Chaudhry, F., Edwards, R., Stefanis, L. and Sulzer, D. (2006). $\alpha$-Synuclein Overexpression in PC12 and Chromaffin Cells Impairs Catecholamine Release by Interfering with a Late Step in Exocytosis. Journal of Neuroscience, 26(46), pp.11915-11922.

Lesage, S., Anheim, M., Letournel, F., Bousset, L., Honoré, A., Rozas, N., Pieri, L., Madiona, K., Dürr, A., Melki, R., Verny, C. and Brice, A. (2013). G51D $\alpha$-synuclein mutation causes a novel Parkinsonianpyramidal syndrome. Annals of Neurology, 73(4), pp.459-471. 
Lively, S. and Schlichter, L. (2013). The microglial activation state regulates migration and roles of matrix-dissolving enzymes for invasion. Journal of Neuroinflammation, 10(75), doi: 10.1186/17422094-10-75.

Longo, D., Fanciulli, A. and Wenning, G. (2015). Multiple-System Atrophy. New England Journal of Medicine, 372(3), pp.249-263.

Luth, E., Bartels, T., Dettmer, U., Kim, N. and Selkoe, D. (2015). Purification of $\alpha$-Synuclein from Human Brain Reveals an Instability of Endogenous Multimers as the Protein Approaches Purity. Biochemistry, 54(2), pp.279-292.

Marttila, R. and Rhine, U. (1991). Progression and survival in Parkinson's disease. Acta Neurologica, 136, pp.24-28.

Miki, Y., Mori, F., Tanji, K. and Wakabayashi, K. (2010). PATHOLOGY OF NEURO-GLIAL $\alpha-$ SYNUCLEINOPATHY (LEWY BODY DISEASE AND MULTIPLE SYSTEM ATROPHY). Hirosaki Medical Journal, 61(Supplement), pp.80-88.

Mitchison, T. and Kirschner, M. (1984). Dynamic instability of microtubule growth. Nature, 312(5991), pp.237-242.

Nagatsu, T. and Sawada, M. (2005). Inflammatory Process in Parkinsons Disease: Role for Cytokines. Current Pharmaceutical Design, 11(8), pp.999-1016.

Neumann, H., Kotter, M. and Franklin, R. (2008). Debris clearance by microglia: an essential link between degeneration and regeneration. Brain, 132(2), pp.288-295.

Paviour, D., Price, S., Lees, A. and Fox, N. (2007). MRI derived brain atrophy in PSP and MSA-P. Journal of Neurology, 254(4), pp.478-481.

Perez, R., Waymire, J., Lin, E., Liu, J., Guo, F. and Zigmond, M. (2002). A role for alpha-synuclein in the regulation of dopamine biosynthesis. Journal of Neuroscience, 22(8), pp.3090-3099 
Perry, V., Cunningham, C. and Holmes, C. (2007). Systemic infections and inflammation affect chronic neurodegeneration. Nature Reviews Immunology, 7(2), pp.161-167.

Prusiner, S., Woerman, A., Mordes, D., Watts, J., Rampersaud, R., Berry, D., Patel, S., Oehler, A., Lowe, J., Kravitz, S., Geschwind, D., Glidden, D., Halliday, G., Middleton, L., Gentleman, S., Grinberg, L. and Giles, K. (2015). Evidence for $\alpha$-synuclein prions causing multiple system atrophy in humans with parkinsonism. Proceedings of the National Academy of Sciences, 112(38), pp.E5308-E5317.

Radford R, Rcom-H'cheo-Gauthier A, Wong MB, Eaton ED, Quilty M, Blizzard C, Norazit A, Meedeniya A, Vickers JC, Gai WP, Guillemin GJ, West AK, Dickson TC, Chung R, Pountney DL. (2015) The degree of astrocyte activation in multiple system atrophy is inversely proportional to the distance to $\alpha$ synuclein inclusions. Molecular and Cellular Neurosciences. 65:68-81.

Reyes, J.; Rey, N.; Bousset, L.; Melki, R.; Brundin, P.; Angot, E (2013). $\alpha$-Synuclein transfers from neurons to oligodendrocytes. Glia, 62, 387-398.

Roodveldt, C., Labrador-Garrido, A., Gonzalez-Rey, E., Lachaud, C., Guilliams, T., FernandezMontesinos, R., Benitez-Rondan, A., Robledo, G., Hmadcha, A., Delgado, M., Dobson, C. and Pozo, D. (2013). Preconditioning of Microglia by $\alpha$-Synuclein Strongly Affects the Response Induced by Tolllike Receptor (TLR) Stimulation. PLoS ONE, 8(11), p.e79160.

Sasaki, Y., Ohsawa, K., Kanazawa, H., Kohsaka, S. and Imai, Y. (2001). Iba1 Is an Actin-Cross-Linking Protein in Macrophages/Microglia. Biochemical and Biophysical Research Communications, 286(2), pp.292-297.

Spillantini, M. and Goedert, M. (2000). The alpha-synucleinopathies: Parkinson's disease, dementia with Lewy bodies, and multiple system atrophy. Annals of the New York Academy of Sciences, 920, pp.16-27. 
Spillantini, M., Schmidt, M., Lee, V., Trojanowski, J., Jakes, R. and Goedert, M. (1997). AlphaSynuclein in Lewy bodies. Nature, 388(6645), pp.839-840.

Stefanova, N., Fellner, L., Reindl, M., Masliah, E., Poewe, W. and Wenning, G. (2011). Toll-Like Receptor 4 Promotes $\alpha$-Synuclein Clearance and Survival of Nigral Dopaminergic Neurons. The American Journal of Pathology, 179(2), pp.954-963.

Su, X., Maguire-Zeiss, K., Giuliano, R., Prifti, L., Venkatesh, K. and Federoff, H. (2008). Synuclein activates microglia in a model of Parkinson's disease. Neurobiology of Aging, 29(11), pp.1690-1701.

Surguchov A. Intracellular Dynamics of Synucleins: "Here, There and Everywhere". (2015) Int Rev Cell Mol Biol. 320:103-69.

Tang, Y. and Le, W. (2015). Differential Roles of M1 and M2 Microglia in Neurodegenerative Diseases. Molecular Neurobiology, 53(2), pp.1181-1194.

Theillet, F., Binolfi, A., Bekei, B., Martorana, A., Rose, H., Stuiver, M., Verzini, S., Lorenz, D., van Rossum, M., Goldfarb, D. and Selenko, P. (2016). Structural disorder of monomeric $\alpha$-synuclein persists in mammalian cells. Nature, 530(7588), pp.45-50.

Tu, P., Galvin, J., Baba, M., Giasson, B., Tomita, T., Leight, S., Nakajo, S., Iwatsubo, T., Trojanowski, J. and Lee, V. (1998). Glial cytoplasmic inclusions in white matter oligodendrocytes of multiple system atrophy brains contain insoluble $\alpha$-synuclein. Annals of Neurology, 44(3), pp.415-422.

Tufekci, K., Meuwissen, R., Genc, S. and Genc, K. (2012). Inflammation in Parkinson's Disease. Advances in Protein Chemistry and Structural Biology,, 88, pp.69-132.

Ubhi, K., Low, P. and Masliah, E. (2011). Multiple system atrophy: a clinical and neuropathological perspective. Trends in Neurosciences, 34(11), pp.581-590. 
Vieira, B., Radford, R., Chung, R., Guillemin, G.and Pountney, D. (2015). Neuroinflammation in Multiple System Atrophy: Response to and Cause of $\alpha$-Synuclein Aggregation. Frontiers in Cellular Neuroscience. 9:437 doi: 10.3389/fncel.2015.00437.

Wang, S., Chu, C., Stewart, T., Ginghina, C., Wang, Y., Nie, H., Guo, M., Wilson, B., Hong, J. and Zhang, J. (2015). $\alpha$-Synuclein, a chemoattractant, directs microglial migration via $\mathrm{H} 2 \mathrm{O} 2$-dependent Lyn phosphorylation. Proceedings of the National Academy of Sciences, 112(15), pp.E1926-E1935.

Webb, J., Ravikumar, B., Atkins, J., Skepper, J. and Rubinsztein, D. (2003). -Synuclein Is Degraded by Both Autophagy and the Proteasome. Journal of Biological Chemistry, 278(27), pp.25009-25013.

Weinreb, P., Zhen, W., Poon, A., Conway, K. and Lansbury, P. (1996). NACP, A Protein Implicated in Alzheimer's Disease and Learning, Is Natively Unfolded. Biochemistry, 35(43), pp.13709-13715.

Wenning, G. and Stefanova, N. (2009). Recent developments in multiple system atrophy. Journal of Neurology, 256(11), pp.1791-1808.

Williams, M., Xiong, C., Morris, J. and Galvin, J. (2006). Survival and mortality differences between dementia with Lewy bodies vs Alzheimer disease. Neurology, 67(11), pp.1935-1941.

Yamasaki, R., Lu, H., Butovsky, O., Ohno, N., Rietsch, A., Cialic, R., Wu, P., Doykan, C., Lin, J., Cotleur, A., Kidd, G., Zorlu, M., Sun, N., Hu, W., Liu, L., Lee, J., Taylor, S., Uehlein, L., Dixon, D., Gu, J., Floruta, C., Zhu, M., Charo, I., Weiner, H. and Ransohoff, R. (2014). Differential roles of microglia and monocytes in the inflamed central nervous system. The Journal of Experimental Medicine, 211(8), pp.1533-1549. 
Yavich, L., Jäkälä, P. and Tanila, H. (2006). Abnormal compartmentalization of norepinephrine in mouse dentate gyrus in $\alpha$-synuclein knockout and A30P transgenic mice. Journal of Neurochemistry, 99(3), pp.724-732.

Yavich, L., Tanilla, H., Vepsalainen, S. and Jakala, P. (2004). Role of $\alpha$-Synuclein in Presynaptic Dopamine Recruitment. Journal of Neuroscience, 24(49), pp.11165-11170. 
$\underline{\text { Highlights }}$

- Multiple system atrophy brain tissue sections show alpha-synuclein-bearing microglia in close proximity to glial cytoplasmic inclusion-bearing oligodendrocytes

- $\quad$ Alpha-synuclein mobilization assay shows microglial-like cells take up alpha-synuclein aggregate, but do not degrade

- Microglial-like cells migrate away from site of uptake to distal site, reducing quantity of residual protein deposit.

- Epothilone D inhibits microglial migration and reduces distal alpha-synuclein-bearing cells 

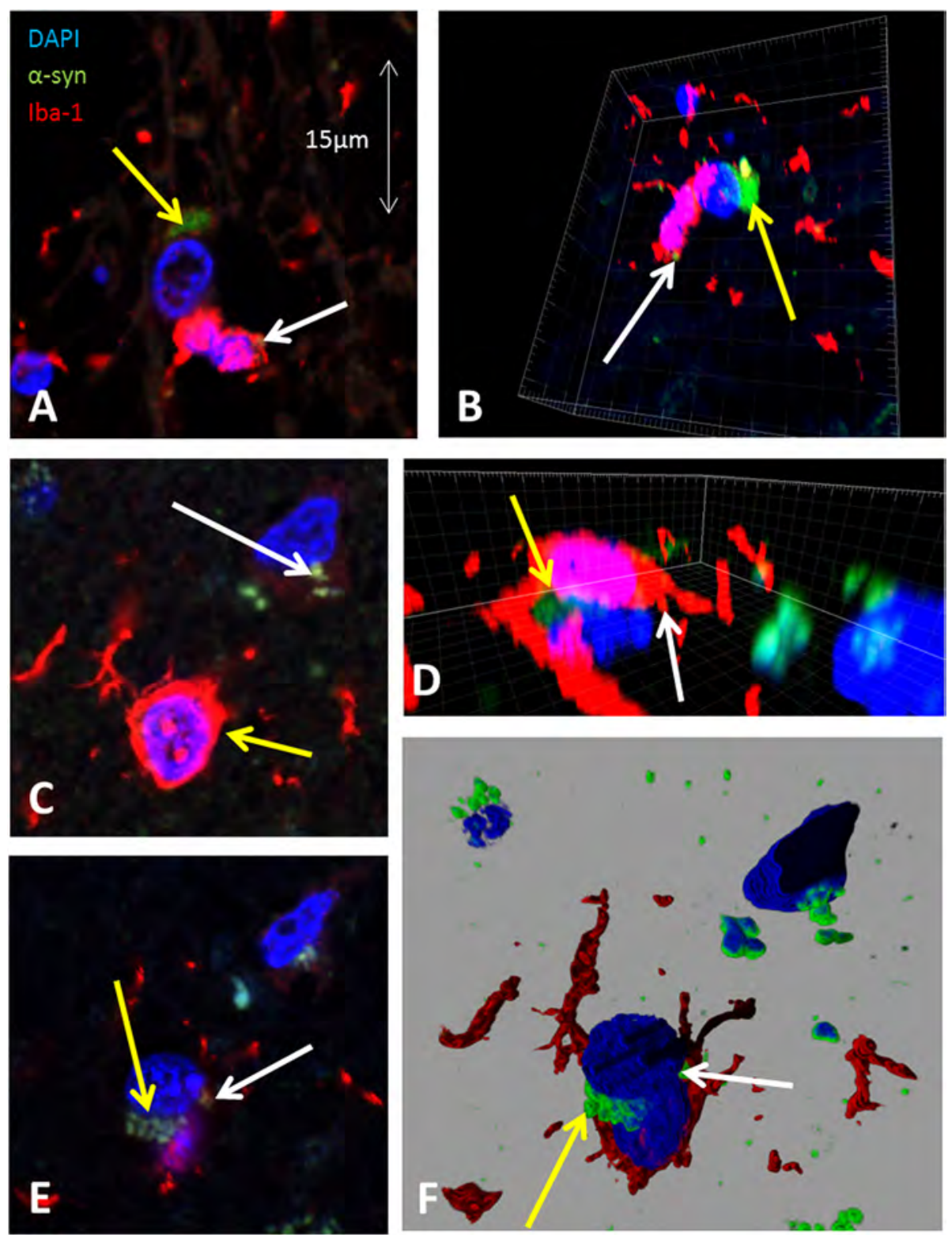

Figure 1 


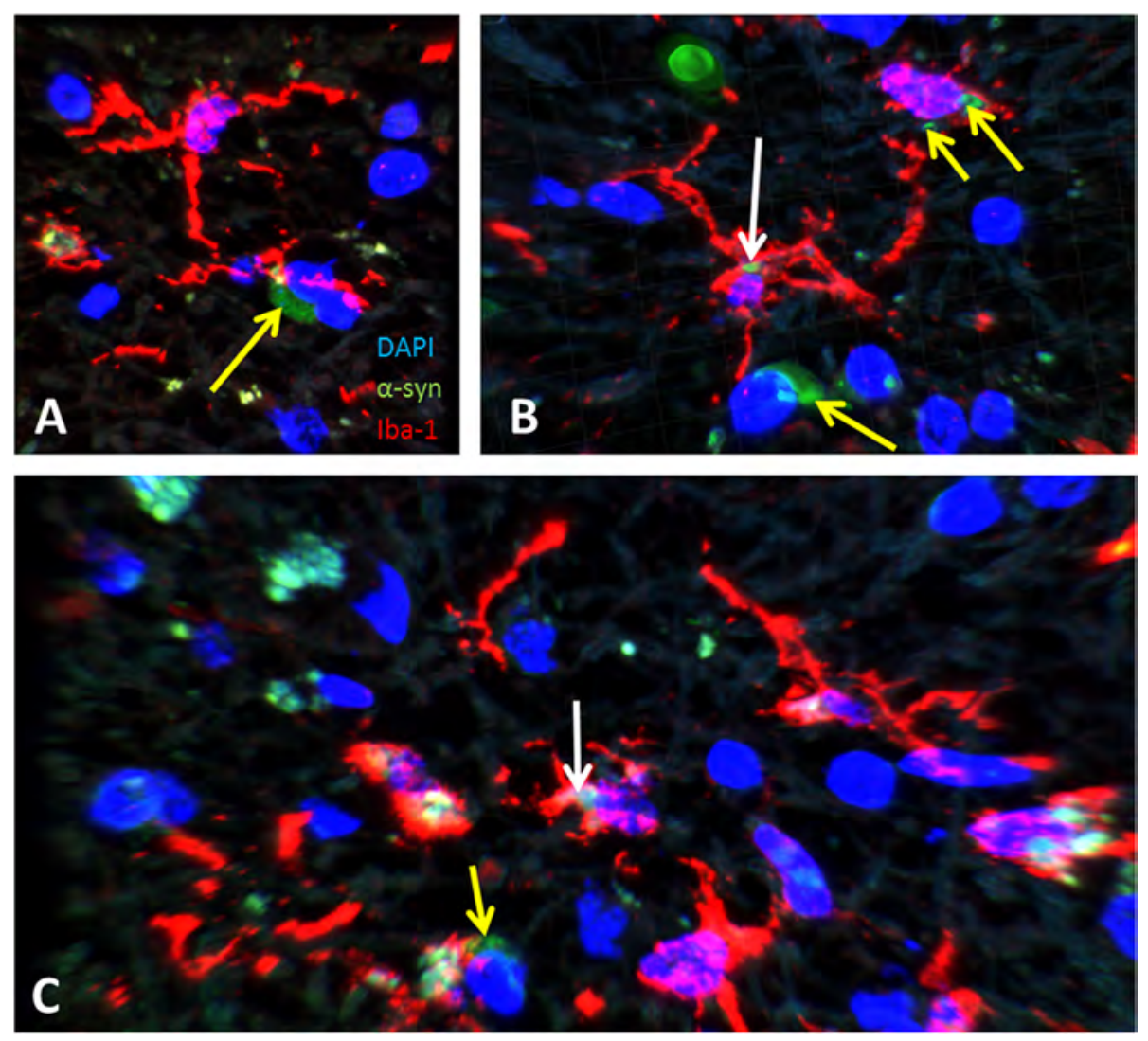

Figure 2 

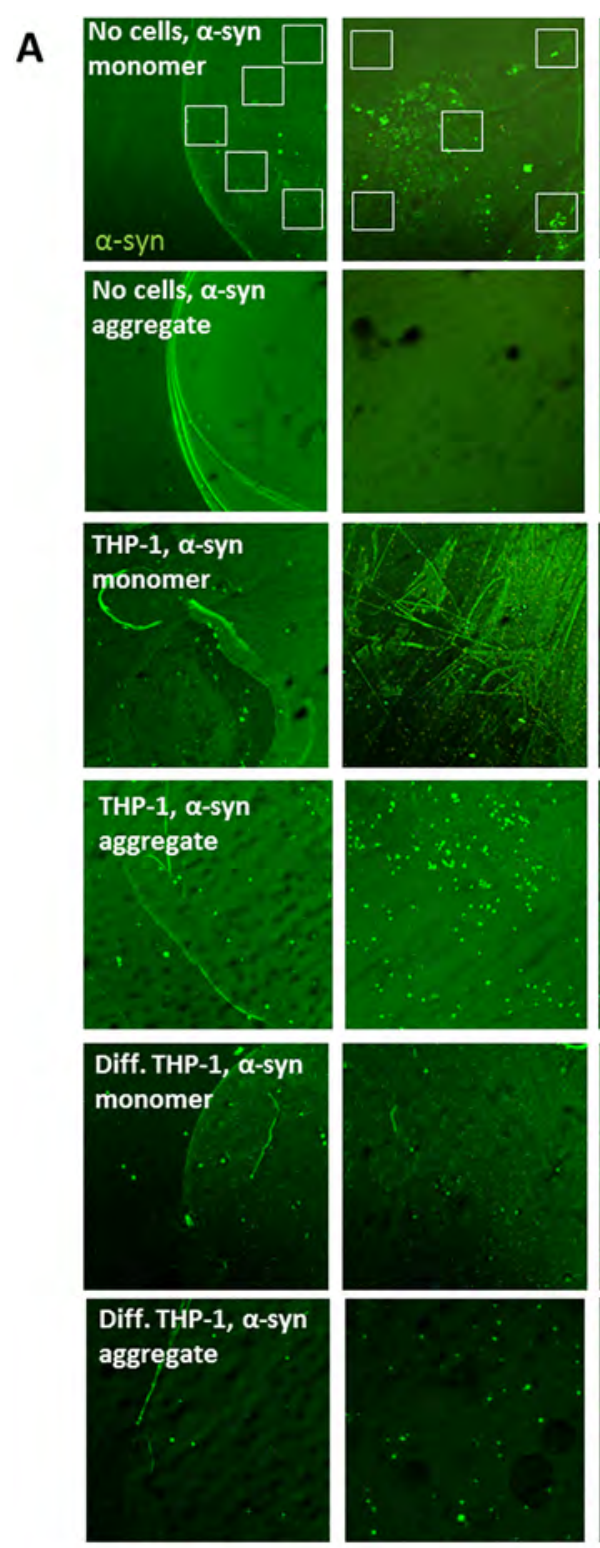

E

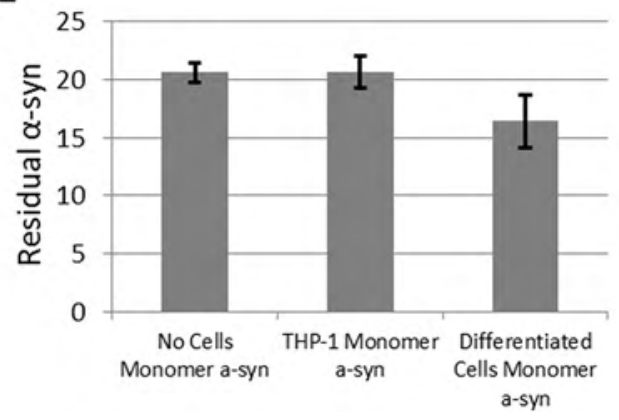

B

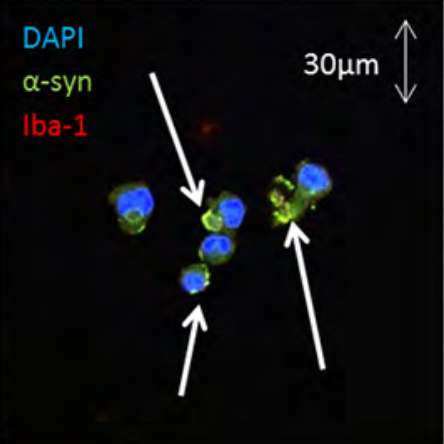

C

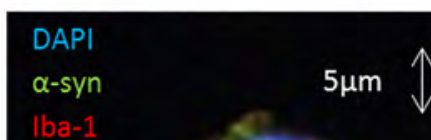

D

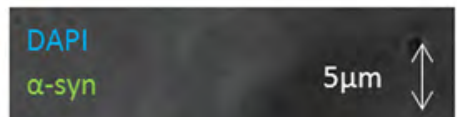

F

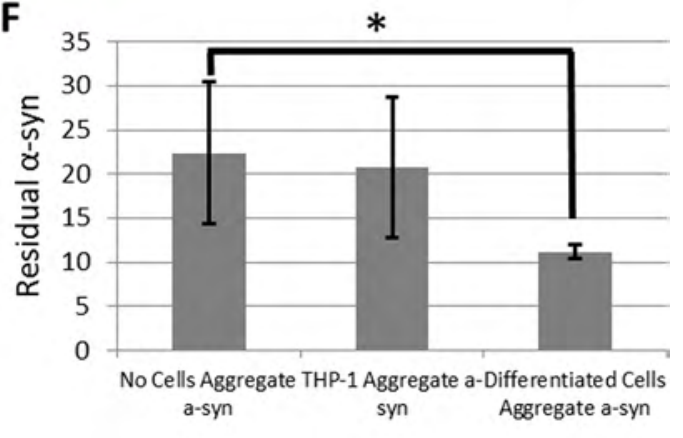


A

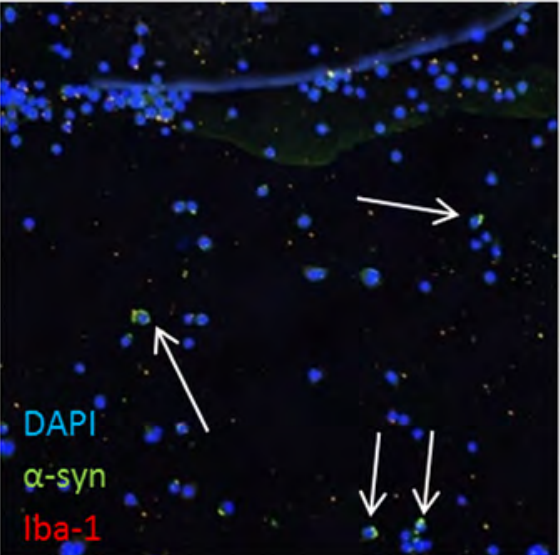

C

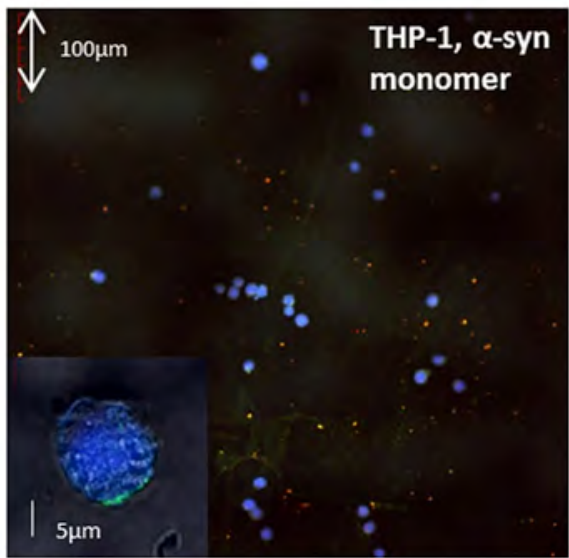

Diff. THP-1, $\alpha$-syn monomer

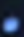

D

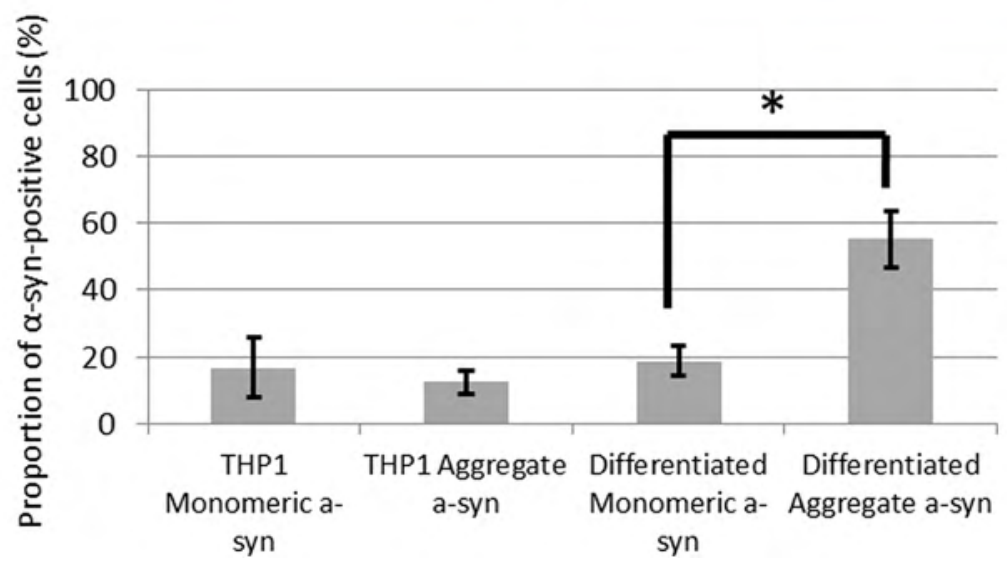

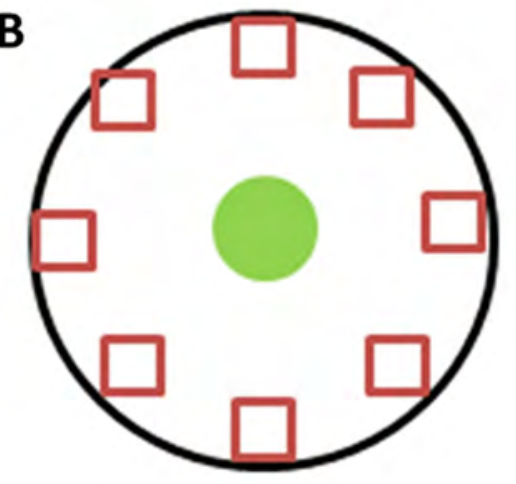
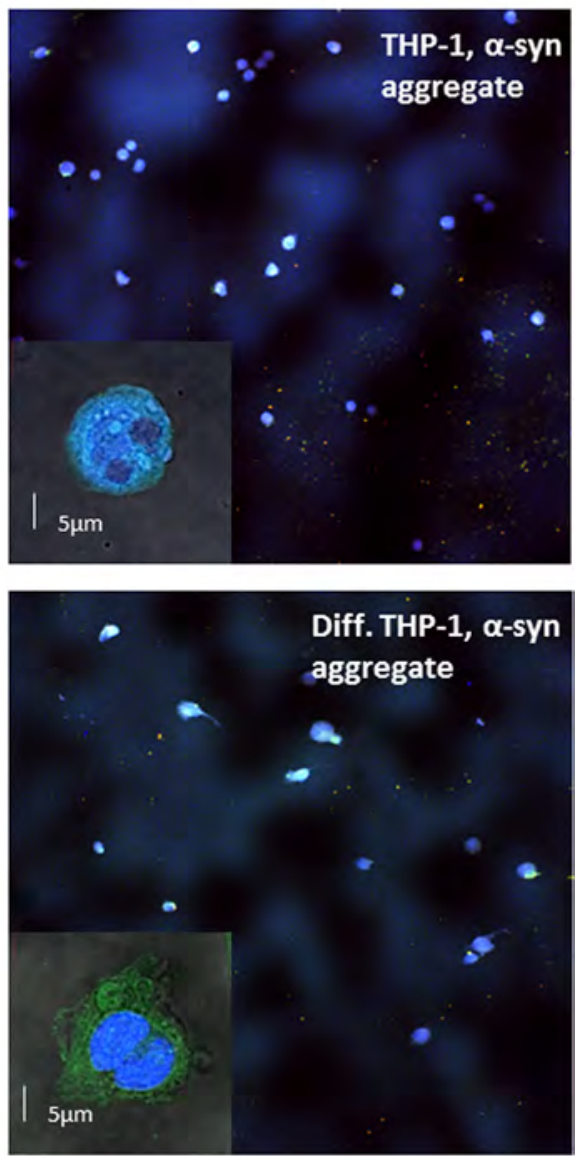
A

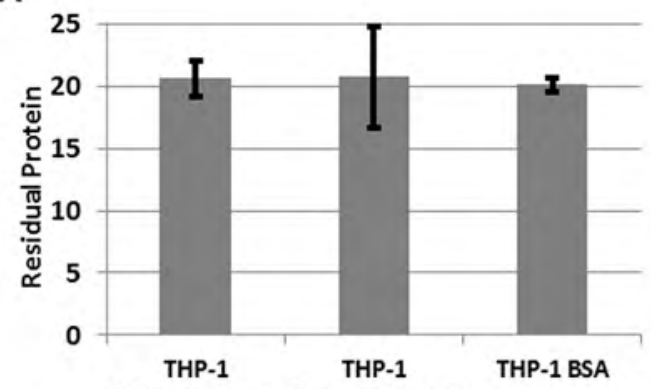

Monomer a-syn Aggregate a-syn

C

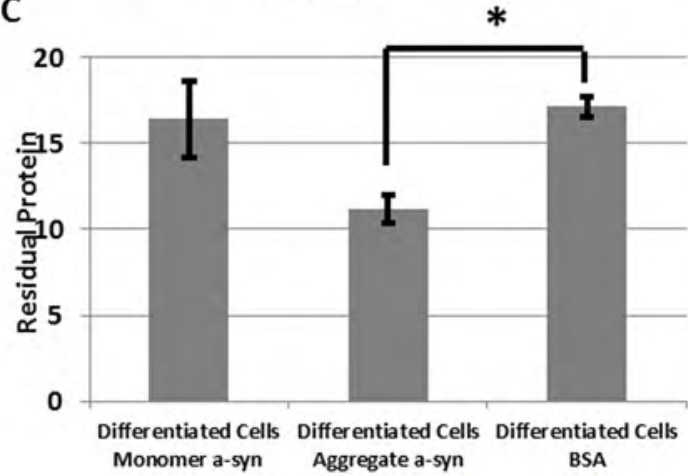

E

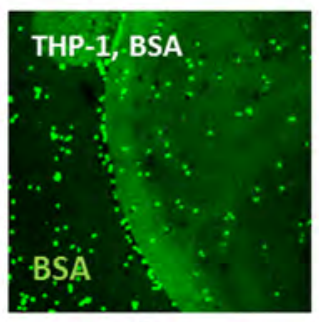

C
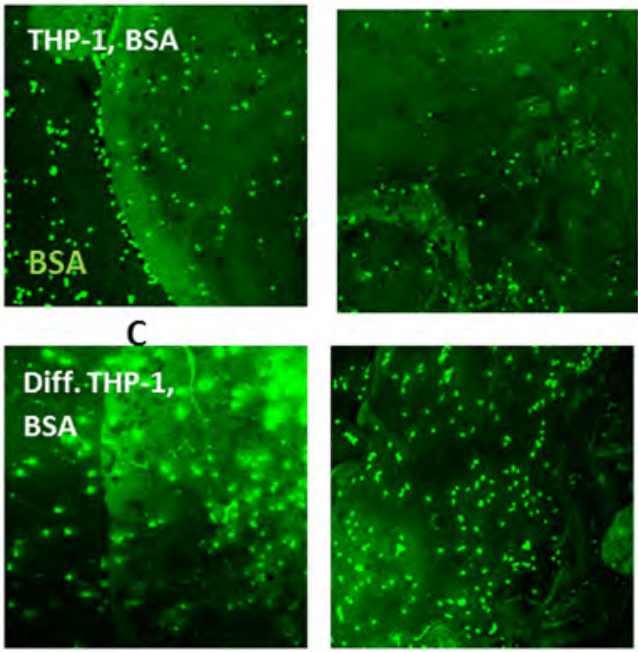

B

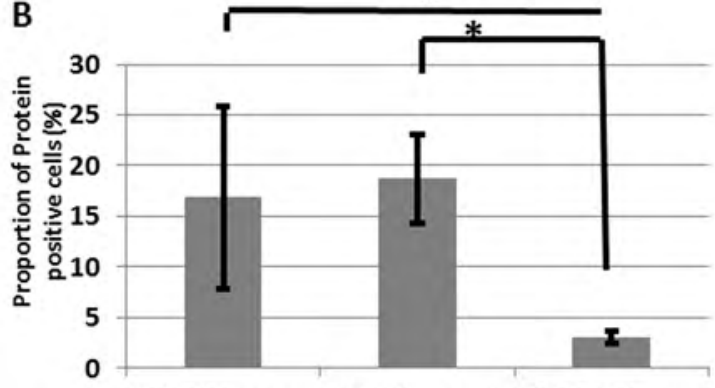

THP-1 Monomer THP-1 Aggregate THP-1 BSA a-syn a-syn
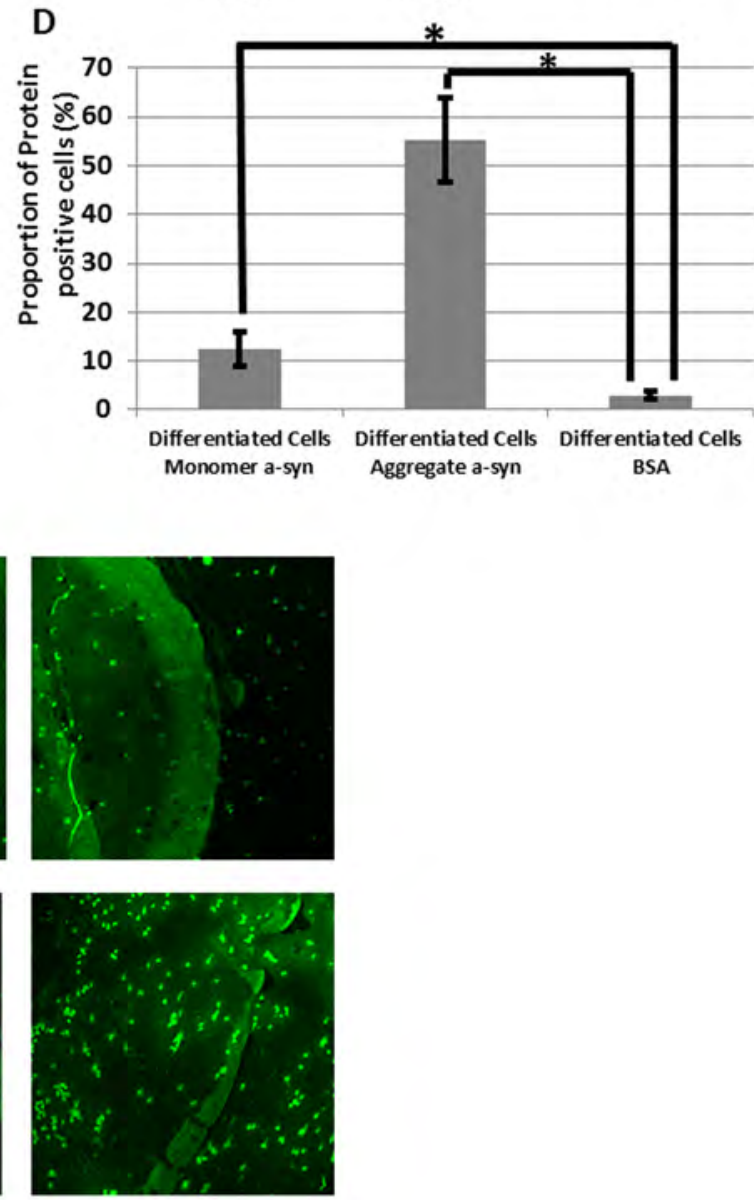

DAPI

$\alpha$-syn

|ba-1
Diff. THP-1,

BSA 
A

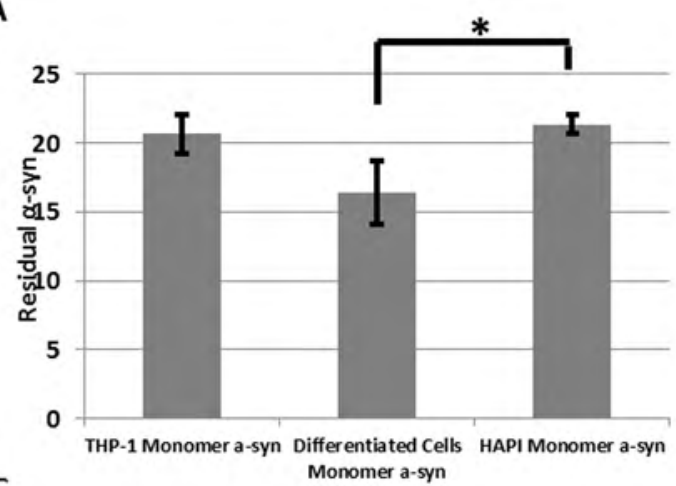

C

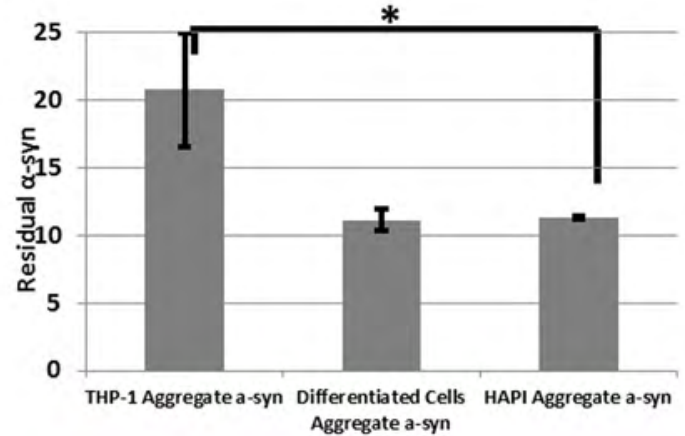

E

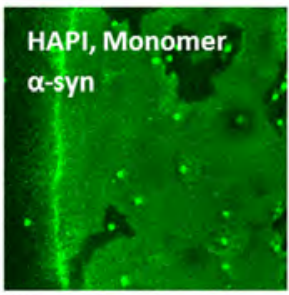

\section{HAPI, Aggregate}

$\alpha$-syn

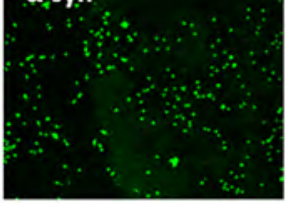

B
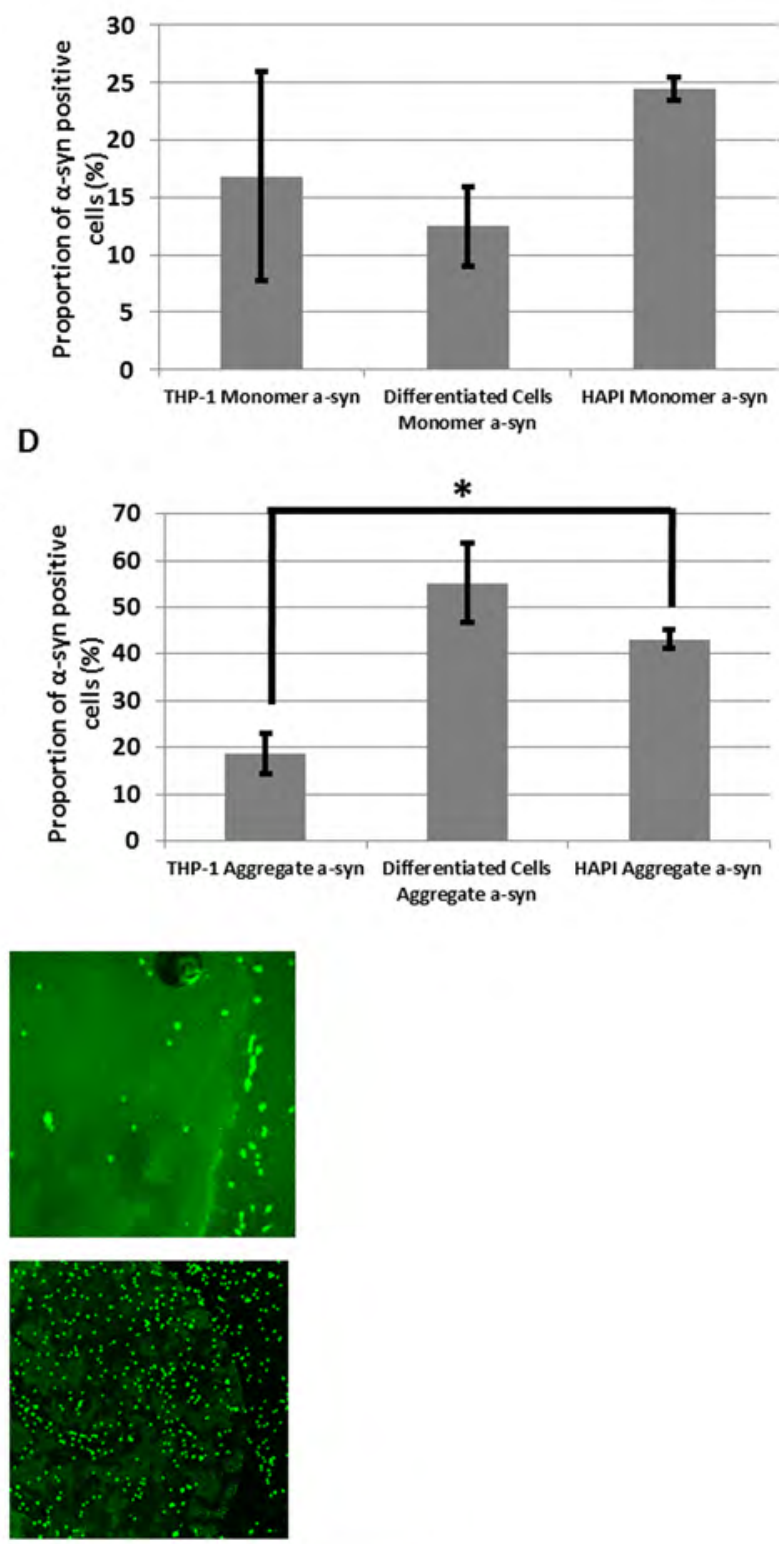
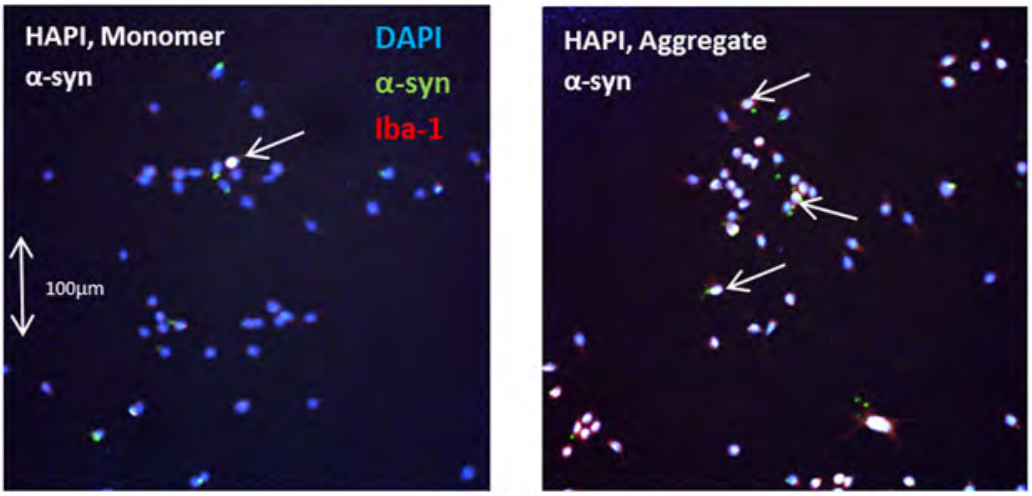

Figure 6 

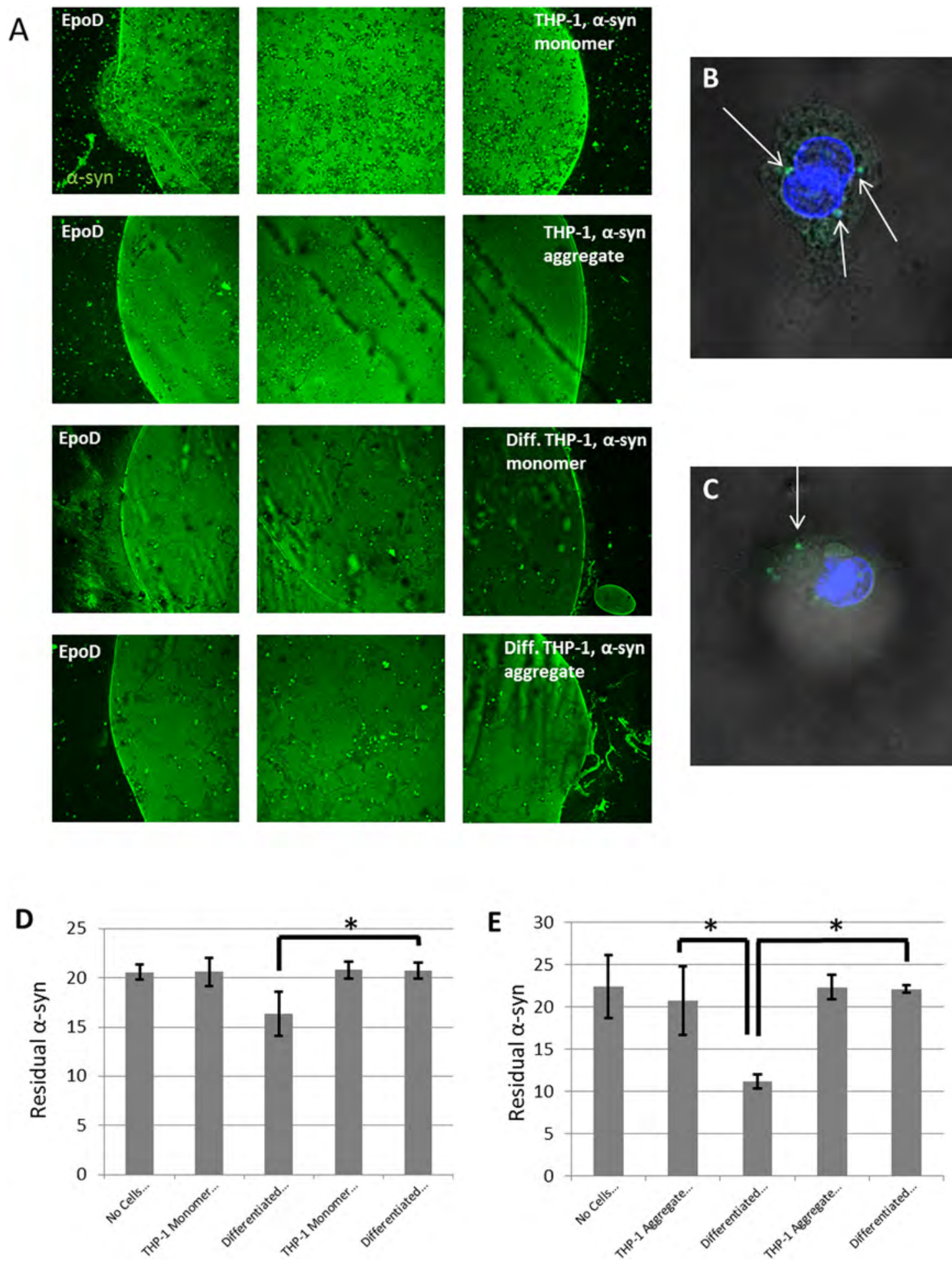

Figure 7 


\section{THP-1, $\alpha$-syn}

monomer

$\uparrow^{100 \mu m}$
EpoD

THP-1, $\alpha$-syn

aggregate

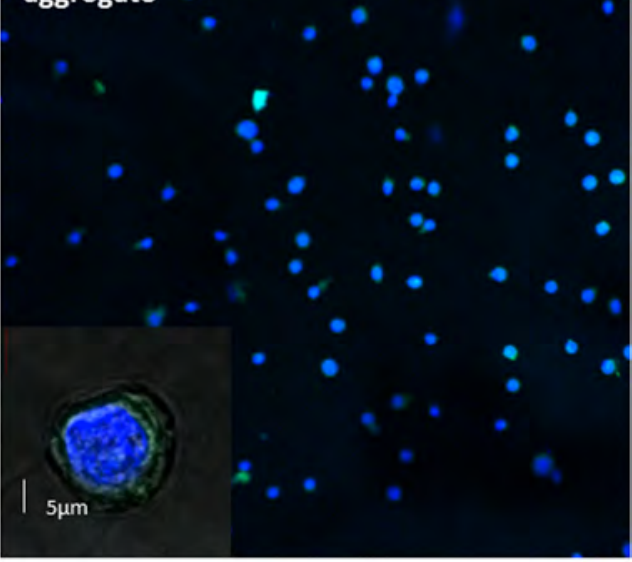

\section{(5)}

Diff. THP-1, $\alpha$-syn

EpoD

\section{monomer}
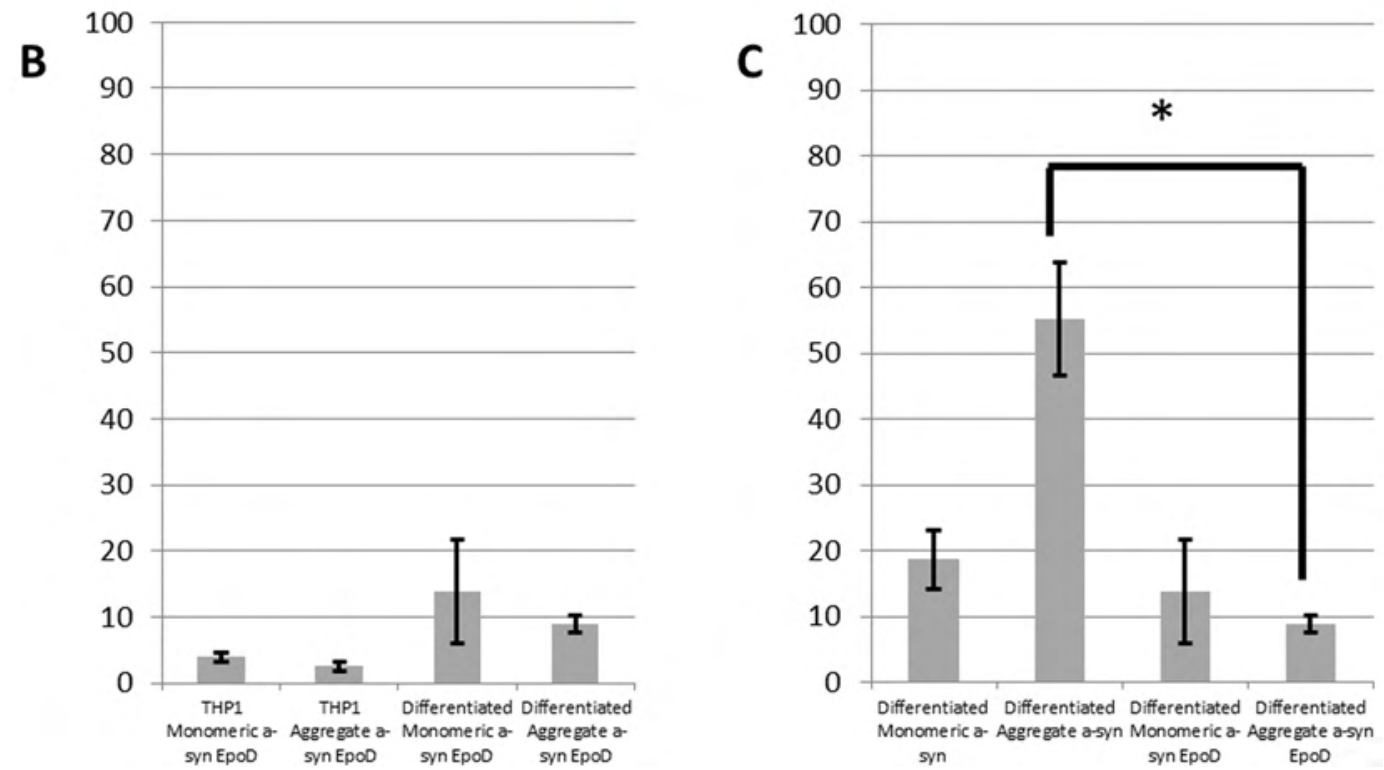

Figure 8 


\section{Accepted Manuscript}

Epothilone D inhibits microglia-mediated spread of alphasynuclein aggregates

Dario Valdinocci, Gary Grant, Tracey Dickson, Dean L. Pountney

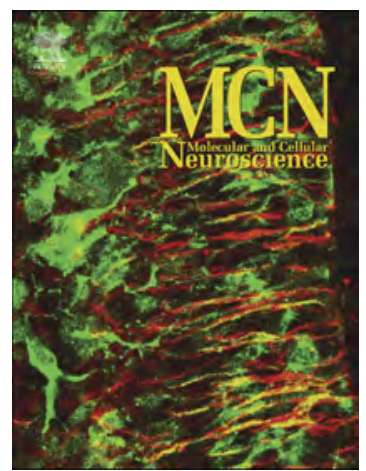

PII:

S1044-7431(17)30350-0

DOI:

doi:10.1016/j.mcn.2018.04.006

Reference:

YMCNE 3308

To appear in:

Molecular and Cellular Neuroscience

Received date:

3 November 2017

Revised date:

19 March 2018

Accepted date:

13 April 2018

Please cite this article as: Dario Valdinocci, Gary Grant, Tracey Dickson, Dean L. Pountney, Epothilone D inhibits microglia-mediated spread of alpha-synuclein aggregates. The address for the corresponding author was captured as affiliation for all authors. Please check if appropriate. Ymcne(2017), doi:10.1016/j.mcn.2018.04.006

This is a PDF file of an unedited manuscript that has been accepted for publication. As a service to our customers we are providing this early version of the manuscript. The manuscript will undergo copyediting, typesetting, and review of the resulting proof before it is published in its final form. Please note that during the production process errors may be discovered which could affect the content, and all legal disclaimers that apply to the journal pertain. 